\title{
Grading evolution and critical state in a discrete numerical model of Fontainebleau sand
}

\author{
M. O. CIANTIA*, M. ARROYO $\dagger$, C. O’SULLIVAN $\ddagger$, A. GENS $\dagger$ and T. LIU $\ddagger$
}

\begin{abstract}
Granular materials reach critical states upon shearing. The position and shape of a critical state line (CSL) in the compression plane are important for constitutive models, interpretation of in situ tests and liquefaction analyses. It is not fully clear how grain crushing may affect the identification and uniqueness of the CSL in granular soils. Discrete-element simulations are used here to establish the relation between breakage-induced grading evolution and the CSL position in the compression plane. An efficient model of particle breakage is applied to perform a large number of tests, in which grading evolution is continuously tracked using a grading index. Using both previous and new experimental results, the discrete-element model is calibrated and validated to represent Fontainebleau sand, a quartz sand. The results obtained show that, when breakage is present, the inclusion of a grading index in the description of critical states is advantageous. This can be simply done using the critical state plane (CSP) concept. A CSP is obtained for Fontainebleau sand.
\end{abstract}

KEYWORDS: discrete-element modelling; particle crushing/crushability; sands; shear strength; stress path

\section{INTRODUCTION}

When sand is subject to shear deformation, it will progress towards a critical state where shear occurs at constant volume and stress. The combinations of stress and volume at the critical state define a critical state line or locus (CSL). These are basic tenets of soil mechanics, which were clearly enunciated more than 50 years ago (Casagrande, 1936; Taylor, 1948; Roscoe et al., 1958). Building upon these principles and using an elasto-plastic formulation the first constitutive models for sand were proposed (Roscoe et al., 1958). Subsequent models using this basis have produced more realistic predictions of sand behaviour (Jefferies, 1993; Manzari \& Dafalias, 1997; Yu, 1998; Gajo \& Wood, 1999; Russell \& Khalili, 2004).

Quite frequently, those models were formulated making use of a state parameter, a measure of the distance between a given state and the CSL. The most popular choice is the state parameter $\psi$ introduced by Been \& Jefferies (1985). $\psi$ is defined as the difference between current void ratio, $e$, and $e_{\mathrm{c}}$, the void ratio on the CSL at the same mean pressure

$$
\psi=e-e_{\mathrm{c}}
$$

The location of the CSL on the compression plane $e-p^{\prime}$ determines $\psi$. Jefferies \& Been (2015) concluded that, although the CSL location is effectively insensitive to fabric, a sand's grading does affect the parameters defining its CSL. Uniformly graded soils tend to have steeper CSLs than well-graded sands and the addition of fines generally increases the slope of the CSL. Jefferies \& Been (2015)

Manuscript received 1 February 2017; revised manuscript accepted 14 February 2018.

Discussion on this paper is welcomed by the editor.

* Formerly Imperial College, London; School of Science and Engineering, University of Dundee, Dundee, UK

(Orcid:0000-0003-1897-4471).

$\dagger$ Department of Civil and Environmental Engineering, Geosciences Division, UPC, Spain.

t Department of Civil and Environmental Engineering, Geotechnics Section, Imperial College, London, UK. address changes to the CSL induced by grading when comparing different soils. However, grading is not considered to vary, but rather to be an intrinsic soil property. These observations are mostly based on the results of triaxial tests on quartz sands of variable fines content, tested at low pressures $(<1 \cdot 2 \mathrm{MPa})$. For these conditions, breakage is generally negligible and soil grading may be assumed constant.

Other materials, such as carbonate sands (Coop \& Airey, 2003), volcanic pumice sands (Pender et al., 2006) and ballast (Indraratna et al., 2015) show significant crushing at pressures well below $1 \mathrm{MPa}$. The CSLs for these materials may still be defined (Coop \& Lee, 1993) and, typically, they appear far steeper in the $e-\log p^{\prime}$ plane than those of quartz sands at the same confining stress level (Coop \& Airey, 2003). For quartz sands tested at large stress $(>5 \mathrm{MPa})$, steepening of the CSL in the $e-\log p^{\prime}$ plane is also clearly visible (Yamamuro \& Lade, 1996). Pressures of this order of magnitude, and above, are present below cone penetration tests (CPTs) or driven pile tips, where crushing of quartz sands does happen (Leung et al., 1996). A provisional conclusion would be that if crushing is present the CSL is steeper.

Adopting a steeper or even bilinear CSL is not particularly problematic; however, the CSL in the compression plane may become non-unique because of crushing. Muir Wood (2007) and Muir Wood \& Maeda (2008) advanced the concept of a non-unique CSL in the compression plane. They introduced the grading state index, $I_{\mathrm{G}}$, to quantify grading evolution. This index, as illustrated in Fig. 1, is computed as the area ratio of the current grading to a limit grading. Using $I_{\mathrm{G}}$ they generalised the CSL to be a critical state plane (CSP), defined in $v(=1+e)-p^{\prime}-I_{\mathrm{G}}$ space. CSLs are sections through the CSP. They argued this concept is relevant for mechanical phenomena that result in a change to the grading, such as internal erosion or crushing. Following this idea, several elasto-plastic constitutive models have been developed incorporating a grading-dependent CSL (Daouadji \& Hicher, 2009; Kikumoto et al., 2010; Liu \& Zou, 2013; Indraratna et al., 2015; Li et al., 2015). Although these models perform well in simulations, there is little direct evidence to support the idea of a CSP or, at a more basic level, to formulate the link between crushing-induced grading 


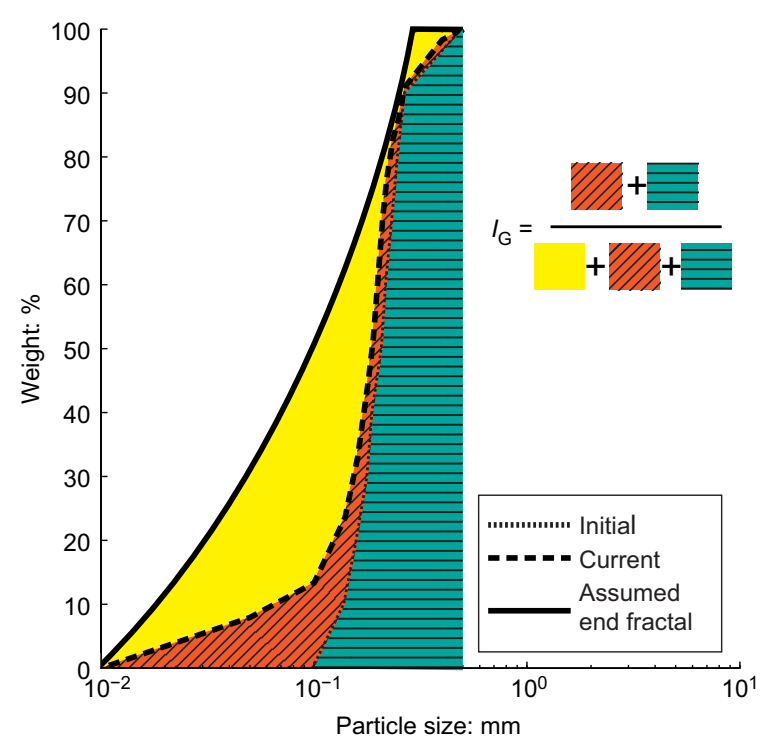

Fig. 1. Muir Wood (2007) grading index definition

evolution and CSL changes. Moreover, that scarce evidence is sometimes contradictory. It is unclear, for instance, if crushing just shifts the CSL in the compression plane, changes its slope, or does both.

Bandini \& Coop (2011) performed triaxial tests on the carbonate Dogs Bay sand with a pre-loading phase to induce crushing and recognised that the CSL of the sand changed, if only slightly. The CSL slope of preloaded sands was smaller than that of normally consolidated sands. CSLs obtained with different amounts of pre-loading were not parallel. Ghafghazi et al. (2014) also concluded that preloadinginduced breakage shifted the CSL of quartzitic Fraser River sand, but they observed parallel shifts. Their specimens were reconstituted after compression and before shearing and this process may have altered the crushing-induced fabric (Muir Wood \& Maeda, 2008). More recently, and by means of a large testing campaign on a ballast-sized material, Xiao et al. (2016) obtained evidence of CSL changes accompanying breakage-induced grading changes. Their results indicate that the CSL does shifts downwards and rotates as breakage increases.

Laboratory exploration of the relation between critical state and breakage is difficult. Even without breakage, the precise observation of critical states is demanding; problems such as localisation, membrane corrections, boundary effects and so on must be overcome (Klotz \& Coop, 2002). Adding breakage to the picture increases the difficulty. It is not currently possible to measure breakage without ending the experiment and so only a single and poorly controlled breakage value results from each test. In the case of quartz sands, the difficulties are compounded by the need for high-pressure equipment.

A major application of discrete-element method (DEM) based simulations in geotechnics is to complement and extend difficult experimental work (O'Sullivan, 2011). DEM studies of unbreakable granular materials at critical state are well developed (Thornton, 2000; Huang et al., 2014c; Kuhn, 2016; Nguyen et al., 2017). Several researchers have also used DEM to study the relationship between grading and critical states. In parametric studies where the grading was systematically varied, it was shown that as the grading becomes broader there is a downward shift in the CSL in the $e-\log p^{\prime}$ space (Muir Wood \& Maeda, 2008; Yan \& Dong, 2011; Li et al., 2015). Some rotation of the CSL has also been observed, with an increase in grading breadth slightly decreasing the CSL slope. No measurable variation in the projection of the CSL on the $q-p^{\prime}$ plane has been reported. These studies, however, do not directly address grading evolution.

Muir Wood \& Maeda (2008) implemented grading evolution into DEM by selectively removing particles. This approach may mimic internal erosion, but is difficult to relate to breakage-driven grading evolution. A clearer link to breakage requires a particle-crushing model. Cheng et al. (2005) used 400 breakable agglomerates to explore the effect of preloading-induced breakage on critical states. They did show a clear effect, with breakage lowering the CSL. However, the void ratios at which the agglomerates packed were far above those typical of quartz sands and the limited number of grains represented resulted in noisy triaxial responses that made precise critical state identification difficult. de Bono \& McDowell (2014) used breakable spherical particles and reproduced the shift in CSL with grading evolution within a range of void ratios representative for quartz sands. However, owing to the small (390) number of particles considered, there was a lot of noise in their data. Hanley et al. (2015) used larger models (24 000 initial particles) whose initial particle size distribution (PSD) matched that of Ham river sand. They obtained smooth triaxial response curves, and showed, again, that allowing crushing lowers the CSL of the sand on the compression plane.

These previous DEM works suffer some important limitations. To begin with, and because of the relatively high computational costs of the models applied, relatively few tests $(<10)$ were simulated in each case, curtailing the scope of the investigations. Furthermore, only Hanley et al. (2015) attempted to track grading evolution during triaxial loading; the trends were qualitatively correct but the amount of breakage computed was far smaller than laboratory observations. Finally, none of these previous DEM studies calibrated and validated the model to represent a specific granular material. This feature hinders application to engineering problems.

The purpose of this contribution is to fill some of these gaps. DEM generated data are used to obtain a more complete and credible view of grading evolution and its relation to critical state. The view is more complete because a larger number of tests are simulated and because grading evolution is tracked systematically, using the grading index $I_{\mathrm{G}}$. The view is more credible because the model is calibrated and then validated to represent a specific quartz sand: Fontainebleau NE34. The results obtained are examined to address the issue of CSL uniqueness, the relevance of the CSP concept and the link between CSL changes and crushing yield.

The paper is organised as follows. First, the general characteristics of the discrete modelling approach followed are outlined. Then the calibration and validation of the model to obtain an analogue of Fontainebleau sand (FS) is presented. The calibration process required additional laboratory experiments to supplement existing test data. The calibrated model is then systematically applied to explore the relations between grading evolution and critical states.

\section{MODELLING APPROACH}

The modelling approach adopted was outlined by Ciantia et al. (2015) and is summarised here for completeness. Spherical particles whose rotation was inhibited were used to capture the rotational resistance that exists between nonspherical grains (Ting et al., 1989; Calvetti, 2008; Arroyo et al., 2011). Using uncrushable particles, Huang et al. (2014a) have shown that samples of spheres with rotation inhibited and with realistic values of inter-particle friction give macroscopic angles of shearing resistance representative 
of sand. CSLs in the $e-\log p^{\prime}$ plane obtained with this method are also reasonable. There are alternatives to blocking rotation such as using non-spherical particles or introducing moment-resisting contact models. The latter approach (Huang et al., 2017) is appropriate to represent interlocking effects, but cannot capture the more significant mechanical effects arising from the divergence of the branch vector and contact normal vectors in non-spherical grains. Whatever their merits, these alternative approaches have the inconvenience of being more computationally demanding, which is a major concern when crushing is allowed.

The contact model uses a simplified Hertz-Mindlin formulation and Coulomb friction. The limit condition at which particle breakage is activated for a given particle was formulated following Russell \& Muir Wood (2009). A particle breaks if the force, $F$, at any of its contacts reaches the limit force

$$
F \leq \sigma_{\lim } A_{\mathrm{F}}
$$

where $\sigma_{\lim }$ is the limit strength of the material and $A_{\mathrm{F}}$ is the contact area. This simple criterion allows separate consideration of particle and contact properties.

To incorporate the natural material variability into the model, the limit strength values for given sphere diameter, $\sigma_{\text {lim }}$, follow a normal distribution. The coefficient of variation of this distribution, 'var', is a material parameter and does not depend on sphere size. The mean value is sizedependent; following McDowell \& De Bono (2013) the mean strength for a sphere of diameter $d, \bar{\sigma}_{\text {lim }}$ is given by

$$
\bar{\sigma}_{\lim }=\sigma_{\lim , 0}\left(\frac{d}{d_{0}}\right)^{-3 / m}
$$

where $\sigma_{\lim , 0}$ is the mean strength at the reference size $d_{0}$. Both $\sigma_{\lim , 0}$ and $m$ are material parameters in the model. Hertzian contact theory is applied to define $A_{\mathrm{F}}$ and the expanded expression for the failure criterion is

$$
\begin{aligned}
F \leq & \left(\sigma_{\lim , 0} f(\operatorname{var})\left(\frac{d}{d_{0}}\right)^{-3 / m}\right. \\
& \left.\times \pi\left\{\frac{3}{4} \frac{\left[\left(1-v_{1}^{2}\right) / E_{1}+\left(1-v_{2}^{2}\right) / E_{2}\right]}{\left[\left(1 / r_{1}\right)+\left(1 / r_{2}\right)\right]}\right\}^{2 / 3}\right)^{3}
\end{aligned}
$$

where $f($ var) indicates the effect of variability of particle strength; $r_{1}$ and $r_{2}$ are the radii of the contacting spheres; and $E_{1}, E_{2}$ and $v_{1}, v_{2}$ are the particle Young's moduli and Poisson ratios, respectively. Note that, since the properties of the two contacting particles appear in the expression for $F$, this is not equivalent to a maximum contact force limit criterion for a specific particle.

Once the limit condition is reached, the spherical particle is split into smaller inscribed tangent spheres, corresponding to the first steps of an Apollonian series. The spawned fragments assume the velocity and material parameters of the original particle apart from the intrinsic strength $\left(\sigma_{\lim }\right)$,

Table 1. Physical properties of Fontainebleau sand

\begin{tabular}{l|c|c|c}
\hline Property & Units & Luong \& Touati (1983) & Seif El Dine et al. (2010) \\
\hline Median grain size, $d_{50}$ & $\mathrm{~mm}$ & $0 \cdot 17$ & $0 \cdot 21$ \\
Uniformity coefficient & & $1 \cdot 48$ & $1 \cdot 52$ \\
Min. void ratio, $e_{\min }$ & & $0 \cdot 54$ & $0 \cdot 54$ \\
Max. void ratio, $e_{\max }$ & & $0 \cdot 94$ & $0 \cdot 94$ \\
Specific gravity, $\rho_{\mathrm{s}}$ & $\mathrm{kN} / \mathrm{m}^{3}$ & $2 \cdot 69$ & $2 \cdot 65$ \\
Min. dry density & $\mathrm{kN} / \mathrm{m}^{3}$ & $13 \cdot 6$ & $13 \cdot 4$ \\
Max. dry density & & $17 \cdot 1$ & $16 \cdot 9$ \\
Shape descriptor & Fairly angular & Unknown \\
\hline
\end{tabular}

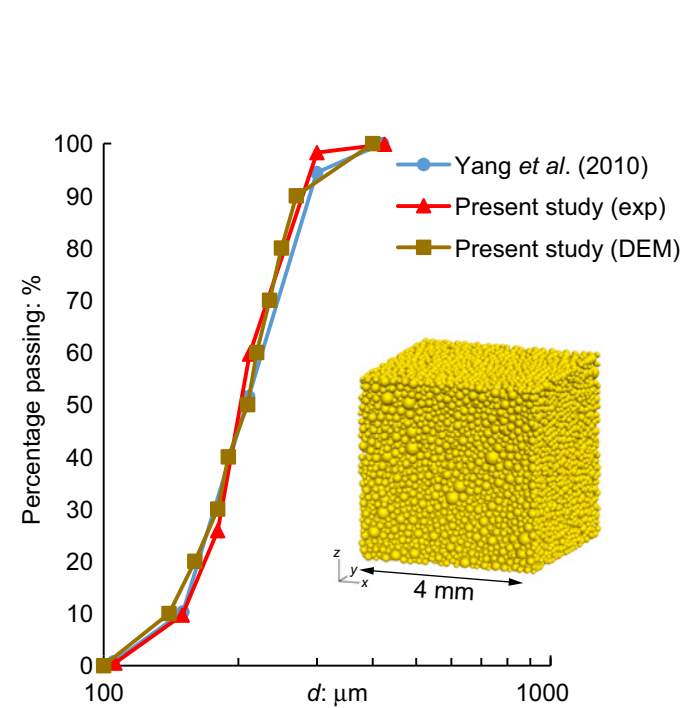

(a)

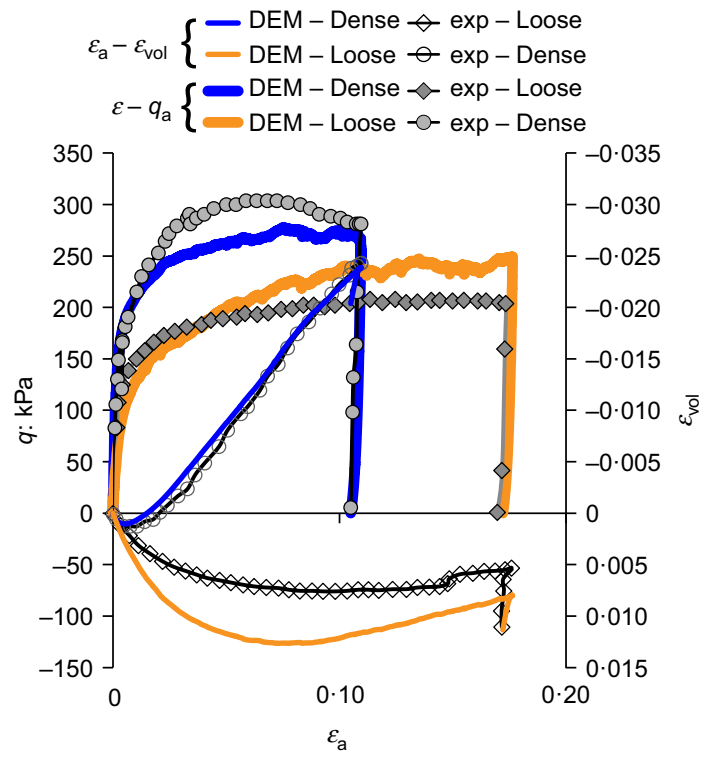

(b)

Fig. 2. Contact model calibration of $E, v, \mu$ : (a) experimental and numerical PSD and DEM model at $5 \mathrm{kPa}$ isotropic compression pressure; (b) DEM simulation of drained triaxial compression test (cell pressure $100 \mathrm{kPa}$; and experimental data from Seif El Dine et al. (2010)) 
Table 2. Calibrated model parameters for Fontainebleau sand

\begin{tabular}{l|c|c|c|c|c|c|c|c|c|c}
\hline$d_{50}: \mathrm{mm}$ & $\mu$ & $E: \mathrm{GPa}$ & $v$ & $\sigma_{\mathrm{lim}, 0}: \mathrm{GPa}$ & $m$ & $d_{0}: \mathrm{mm}$ & Var & $d_{\mathrm{c}} / d_{50}$ & $d_{\max }: \mathrm{mm}$ & $d_{\min }: \mathrm{mm}$ \\
\hline 0.21 & 0.275 & 21.6 & 0.2 & 1.9 & 10 & 2 & 0.36 & 0.55 & 0.27 & 0.01 \\
\hline
\end{tabular}

which is randomly sampled from the corresponding distribution. A fraction of the broken particle volume is lost upon breakage; for solid grains it is assumed that the material lost corresponds to fines. For microporous particles like those of pumice sand, this volume lost may also represent internal particle porosity (Ciantia et al., 2016a). As the number of fragments spawned increases, the amount of volume lost at each breakage reduces, but the computational cost increases. Ciantia et al. (2016b) concluded that splitting into a 14-ball tangent sphere configuration can adequately represent macroscopic behaviour. Data confirming the minimal effect of volume loss on the results presented in this contribution are included in the Appendix to the paper. A numerically motivated comminution limit, $d_{\mathrm{c}}$, is imposed to stop crushing of smaller particles.

The grading index, $I_{\mathrm{G}}$, is computed continuously during each simulation. The limit grading is given by a fractal distribution with fractal dimension $\omega=2 \cdot 6$; this distribution can be expressed (Einav, 2007)

$$
\frac{M_{(L<d)}}{M_{\mathrm{T}}}=\frac{d^{3-\omega}-d_{\min }^{3-\omega}}{d_{\max }^{3-\omega}-d_{\min }^{3-\omega}}
$$

where $M_{\mathrm{T}}$ is the total mass; $M_{(L<d)}$ is the mass of particles smaller than $d ; d_{\max }$ and $d_{\min }$ are, respectively, the maximum and minimum particle sizes assumed for the limit distribution. The same limit distribution formula, but now with $d_{\text {max }}$ given by the smallest particle created during the crushing event, is used during post-processing to assign a size distribution to the volume lost at each crushing event.

Ciantia et al. (2015) showed that the model formulation is scalable and computationally efficient. They matched quantitatively the oedometric behaviour of several granular materials, capturing the at-rest earth pressure coefficient and the changes in grain size distribution - although $I_{\mathrm{G}}$ was not used and grain size distribution curves were directly compared. Parametric analyses to explore the macroscopic effect of several microscopic variables are presented in Ciantia et al. (2015) and Ciantia et al. (2014). The model was later applied to study CPTs in crushable soils, successfully capturing physical calibration chamber responses (Ciantia et al., 2016a). The model can be used to explore soil constitutive behaviour: Ciantia et al. (2016b) studied the contribution of crushing to the incremental response of granular soils in triaxial conditions.

For the simulations described here, a cubic volume was filled with particles, using the radius expansion method, to obtain a representative volumetric element (REV). The specimen boundaries were defined using smooth 'wall' elements, which ensure that principal axes of stress and strain are coincident with the cube axes. A servo-controlled motion of these cube walls applies pre-defined stress paths. Gravity was set to zero. The crushing model was implemented on the PFC3D code (Itasca, 2017), which is used for all simulations.

\section{A DISCRETE NUMERICAL MODEL FOR FONTAINEBLEAU SAND}

Fontainebleau sand is a fine silica sand extensively used in geotechnical research. Most properties of FS have appeared reasonably consistent across the years (Table 1). One relevant exception is the shape, which is described differently by different researchers, who have used descriptors ranging from angular to rounded (Altuhafi et al., 2013). Particle sizes for the numerical cubical cell are selected to match closely the PSD of Fontainebleau NE34 sand (Fig. 2(a)), with particle diameters ranging from $0 \cdot 1$ to $0 \cdot 4 \mathrm{~mm}$. Results from a previous study (Ciantia et al., 2016b) indicate that, for this sand, a cube with side lengths of $4 \mathrm{~mm}$ containing 10000 particles (Fig. 2(a)) is large enough to obtain smooth numerical responses and can be considered as an REV. The limit fractal distribution was assumed to have $d_{\max }=0.27 \mathrm{~mm}$ and $d_{\min }=0.01 \mathrm{~mm}$.

The calibrated model parameters are collected in Table 2. The contact model parameters $(E, v, \mu)$, where $\mu$ is the coefficient of inter-particle friction, were calibrated by simulating two drained triaxial tests on dense and loose specimens at low confining pressure $(100 \mathrm{kPa})$ as reported by Seif El Dine et al. (2010) (Fig. 2(b)). The size-specific particle

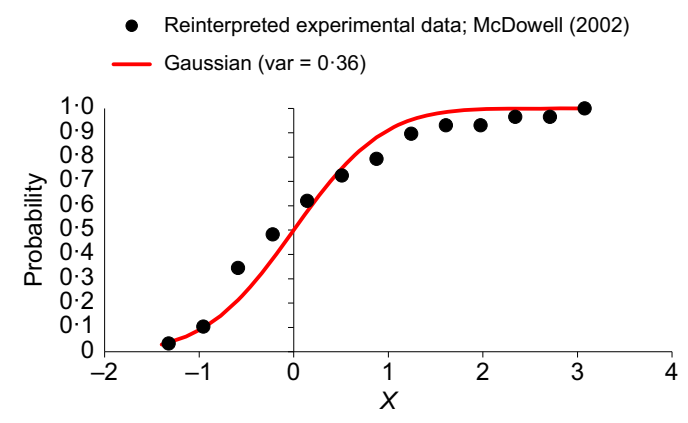

(a)

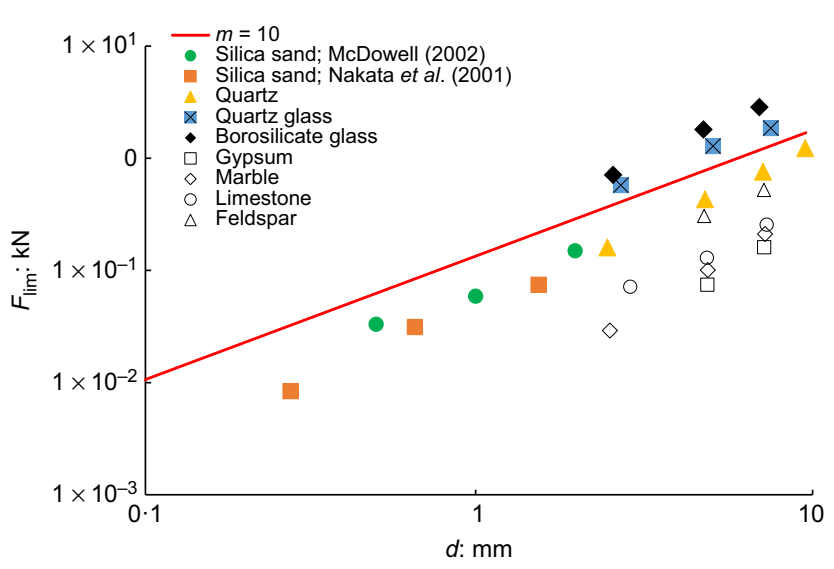

(b)

Fig. 3. Calibration of crushing-related parameters of the contact model using flat-platen single-particle crushing test data: (a) data from silica sand showing crushing force at fixed grain size fitted with normalised Gaussian to adjust var. $X$ is a normalised Gaussian distribution of grain strengths, for particles having the same nominal diameter $\boldsymbol{X}=(\boldsymbol{x}-\overline{\boldsymbol{\mu}}) / \boldsymbol{\sigma}=(\boldsymbol{x} / \overline{\boldsymbol{\mu}}-1) / \mathrm{var}=\left(\boldsymbol{x}_{\boldsymbol{n}}-1\right) / \mathrm{var}$; (b) average crushing forces at different sizes for various materials and fitted size-dependence expression $F_{\lim }=\sigma_{\lim } A_{\mathrm{F}}$ with parameter $m=10$ and mean particle strength $\sigma_{\lim , 0}=1.9 \mathrm{GPa}$ (reinterpreted from Ciantia et al. (2015)) 


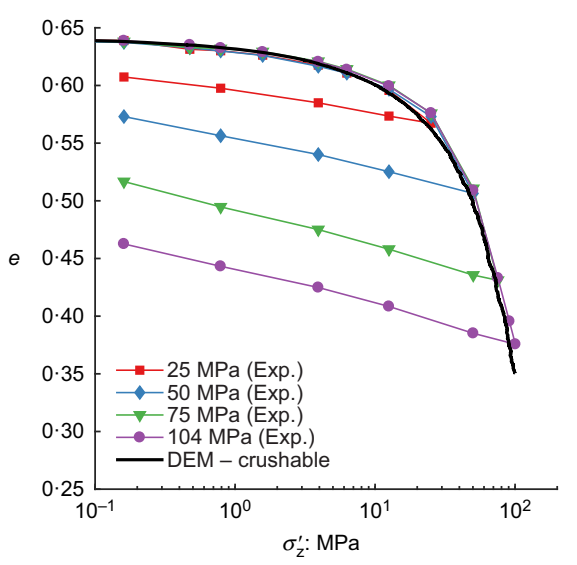

(a)

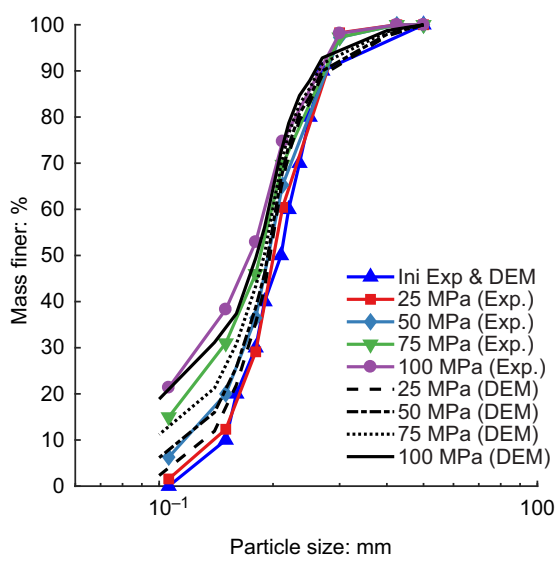

(b)

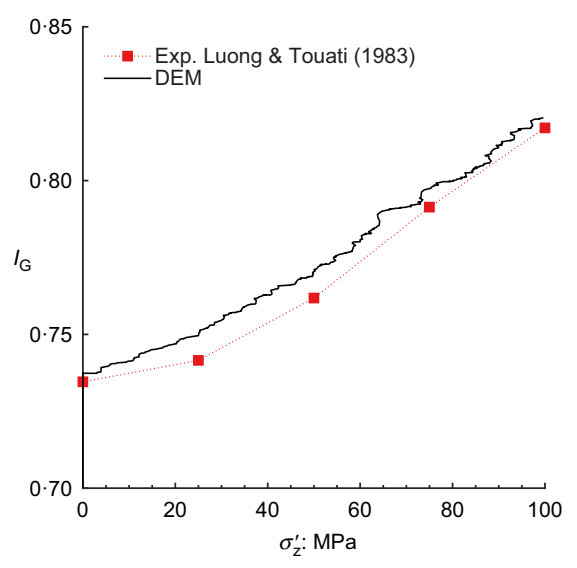

(c)

Fig. 4. Crushing model validation by DEM simulation of high-pressure oedometric compression tests in terms of: (a) vertical effective stress plotted against void ratio; (b) PSD evolution; (c) grading index evolution with vertical effective stress

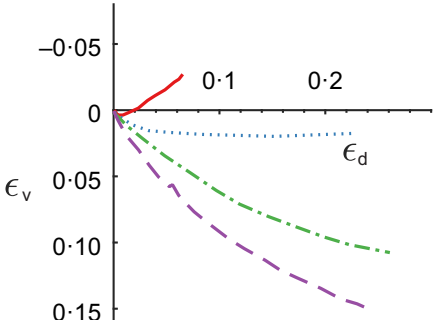

(a)

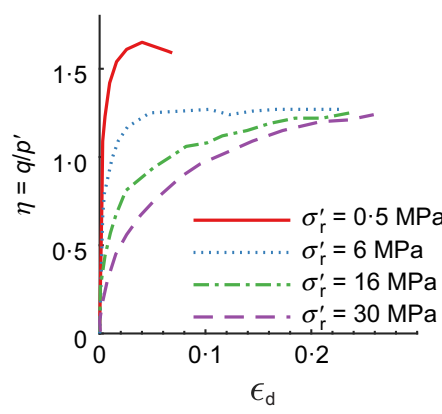

(d)

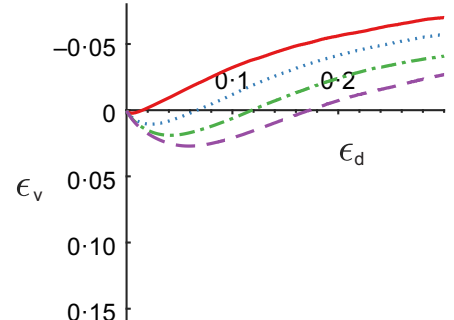

(b)

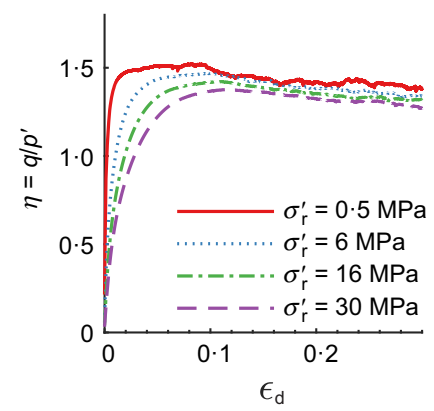

(e)

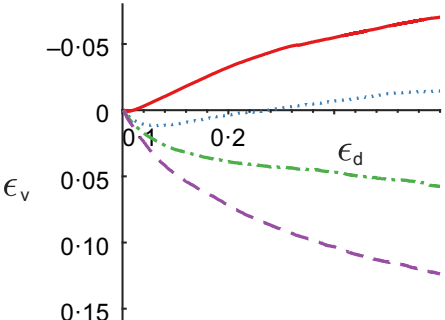

(c)

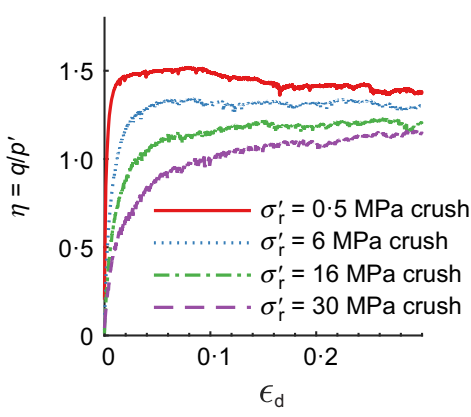

(f)

Fig. 5. DEM crushing model validation: high-confinement-pressure drained triaxial compression tests by Luong \& Touati (1983) were simulated: (a) experimental; (b) numerical without crushing; (c) with crushing volumetric response; (d) experimental; (e) numerical without crushing; (f) with crushing stress-strain response

strength variability parameter (var) was obtained by fitting a Gaussian distribution curve (Fig. 3(a)) to single grain crushing experiments on another silica sand reported by McDowell (2002). The parameter $m$ (equations (3) and (4)) was obtained by considering experimental data on flat-platen single-particle crushing forces on different silica sands (Fig. 3(b)). This dataset also indicated a likely range for $\sigma_{\lim , 0}$.

The specific $\sigma_{\lim , 0}$ value was calibrated to capture the apparent yield point observed in a single oedometer test with a maximum applied vertical stress of $100 \mathrm{MPa}$ carried out on FS NE34 at Imperial College (Fig. 4). To test the model's validity, three additional oedometric tests with maximum stresses of $25 \mathrm{MPa}, 50 \mathrm{MPa}$ and $75 \mathrm{MPa}$ were also performed (Fig. 4). The experimental PSDs were obtained by sieving after unloading the samples (Fig. 4(b)). The $I_{\mathrm{G}}$ describing the grading evolution observed in these experiments is given in Fig. 4(c). The corresponding DEM simulation data presented in Figs 4(b) and 4(c) capture the experimental grading evolution well; this can be taken as a first validation of the model.
Luong \& Touati (1983) reported a series of high-pressure isotropic and triaxial compression tests on dense FS, including the PSDs of the specimens after testing. To further validate the DEM model, the variations in mobilised strength and dilatancy with shear strain during these tests are compared with DEM data for equivalent simulations in Fig. 5. Two sets of simulations are presented: one in which crushing was disabled, another with crushing activated. When crushing was disabled, the simulations did not reproduce the suppression of dilatancy associated with high confining pressures. When crushing was activated, this feature was captured as in the experimental data. A comparison between the simulated and experimental results reveals a reasonable agreement, taking into account that: the experimental specimens had slightly lower void ratio before shearing $(\Delta e \approx 0.03$ on average); there was no attempt to match initial fabric, platen lubrication (Bishop \& Green, 1965) or membrane effects (Colliat-Dangus et al., 1988); and, finally, the above-mentioned differences between batches of FS might have affected calibration. 
Grading evolution data for these experiments and simulations are plotted in Fig. 6, which also includes additional experimental data from isotropic compression tests. The $I_{\mathrm{G}}$ data from equivalent DEM simulations using the crushing model agree well with the experimental data. There is a small discrepancy in the mobilised friction values $(\eta)$ at critical state, which show poorer convergence in DEM simulations than in the experimental data. As shown in the Appendix, this is mostly a consequence of volume loss in the model.

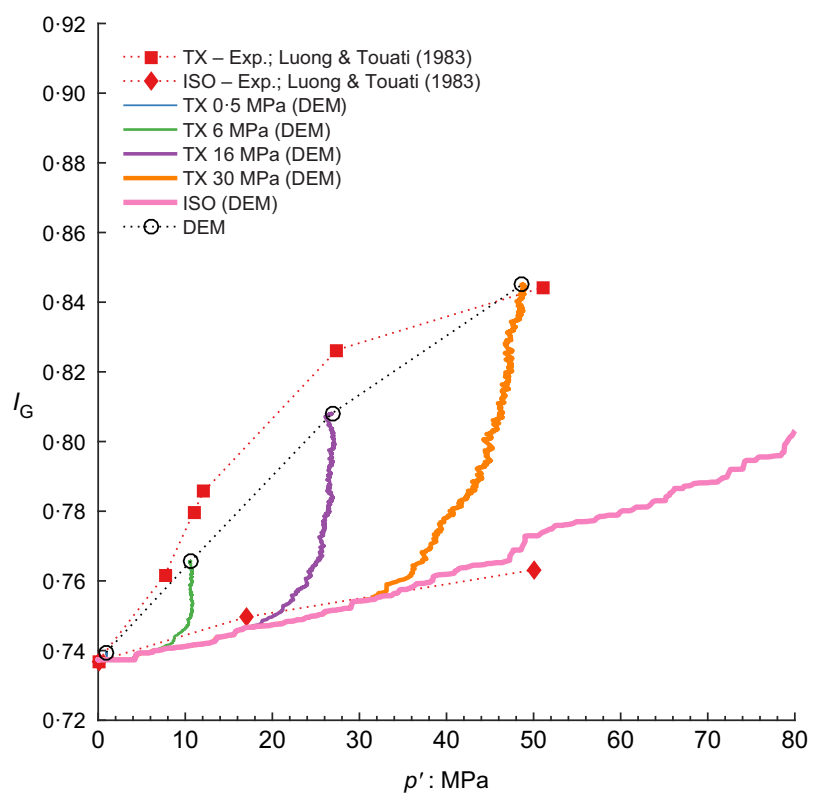

Fig. 6. DEM crushing model validation: isotropic compression (ISO) and high-confinement-pressure drained triaxial (TX) compression tests by Luong \& Touati (1983). Experimental and numerical grading index, $I_{\mathrm{G}}$, evolution

\section{CRITICAL STATES AND GRADING EVOLUTION}

Having established that the DEM model of Fontainebleau sand can capture experimental data, triaxial test simulations were carried out to establish the effects of grading evolution on critical states. The initial void ratio for all tests was 0.65 , equivalent to a relative density of $65 \%$ for NE34 FS (Table 1). The tests were organised in six series (Table 3), characterised by their pre-consolidation state and by the crushing model status (active/inactive). Each series comprised 12 tests so that there were four isotropic confining pressures $\left(p_{0}^{\prime}, 0 \cdot 5,6,16\right.$, $30 \mathrm{MPa})$ from which shearing started and three different stress paths (constant confining pressure, $\dot{\sigma}_{x}^{\prime}=\dot{\sigma}_{y}^{\prime}=0$; constant mean stress, $\dot{p}^{\prime}=0$; constant vertical stress $\dot{\sigma}_{z}^{\prime}=0$ ).

Each test simulation continued to a deviatoric strain of $30 \%$. At that strain level, critical state conditions (i.e. a constant level of mobilised shear strength and void ratio) could be identified from the simulations. Fig. 7 illustrates a typical result; the response for the $\dot{\sigma}_{z}^{\prime}=0$ stress path is more dilatant than that for the $\dot{p}^{\prime}=0$ test, which in turn is more dilatant than the conventional triaxial path $\left(\dot{\sigma}_{x}^{\prime}=\dot{\sigma}_{y}^{\prime}=0\right)$. The observed stress path effect reflects the evolution of $p^{\prime}$ during shearing; similar results are reported from laboratory tests on sand (Vaid \& Sasitharan, 1992; Azeiteiro et al., 2017).

Critical states: crushable as opposed to uncrushable material

In test series A and B, triaxial shear always started from a normally consolidated state; crushing was always active in series A and always inactive in series B. Fig. 8(a) presents the stress paths for all of these simulations; the peak and critical state stresses are identified on each path. Fig. 8(b) presents the difference between peak and critical state friction angles as a function of confining pressure. For the crushable material the difference between peak and critical state strengths practically disappears at high pressures; this brittle-to-ductile transition has been reported in prior experimental research (Lo \& Roy, 1973; Yamamuro \& Lade, 1996) and in DEM simulations by Hanley et al. (2015).

The isotropic compression and shearing paths from test series A and B are presented in $e-\log p^{\prime}$ space in Fig. 9. The

Table 3. Simulation test series to explore critical states of the FS analogue

\begin{tabular}{|c|c|c|c|c|c|}
\hline $\begin{array}{l}\text { Test } \\
\text { series }\end{array}$ & $\begin{array}{l}\text { Isotropic stress before } \\
\text { shearing, } p_{0}^{\prime}: \mathrm{MPa}\end{array}$ & Shear paths & $\begin{array}{l}\text { Isotropic pre-consolidation } \\
\text { stress, } p_{\mathrm{c}}^{\prime}: \mathrm{MPa}\end{array}$ & OCR & Crushing \\
\hline A & $0 \cdot 5,6,16,30$ & $\begin{array}{l}\dot{\sigma}_{x}^{\prime}=\dot{\sigma}_{y}^{\prime}=0 \\
\dot{p}^{\prime}=0\end{array}$ & - & 1 & Always active \\
\hline B & $0 \cdot 5,6,16,30$ & $\begin{array}{l}\dot{\sigma}_{z}^{\prime}=0 \\
\dot{\sigma}_{x}^{\prime}=\dot{\sigma}_{y}^{\prime}=0 \\
\dot{p}^{\prime}=0\end{array}$ & - & 1 & De-activated \\
\hline $\mathrm{C}$ & 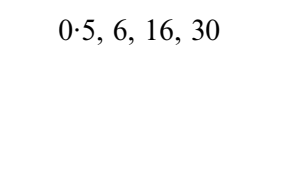 & $\begin{array}{l}\dot{\sigma}_{z}^{\prime}=0 \\
\dot{\sigma}_{x}^{\prime}=\dot{\sigma}_{y}^{\prime}=0 \\
\dot{p}^{\prime}=0 \\
\dot{\sigma}_{z}^{\prime}=0\end{array}$ & 60 & $2,3 \cdot 75,10,120$ & Active during isotropic pre-loading \\
\hline $\mathrm{D}$ & $0 \cdot 5,6,16,30$ & $\begin{array}{l}\dot{\sigma}_{x}^{\prime}=\dot{\sigma}_{y}^{\prime}=0 \\
\dot{p}^{\prime}=0 \\
\dot{\sigma}_{z}^{\prime}=0\end{array}$ & 100 & $3 \cdot 3,6 \cdot 25,16 \cdot 7,200$ & Active during isotropic pre-loading \\
\hline $\mathrm{E}$ & $0 \cdot 5,6,16,30$ & $\begin{array}{l}\dot{\sigma}_{x}^{\prime}=\dot{\sigma}_{y}^{\prime}=0 \\
\dot{p}^{\prime}=0 \\
\dot{\sigma}_{z}^{\prime}=0\end{array}$ & 60 & $2,3 \cdot 75,10,120$ & Always active \\
\hline $\mathrm{F}$ & $0 \cdot 5,6,16,30$ & $\begin{array}{l}\dot{\sigma}_{x}^{\prime}=\dot{\sigma}_{y}^{\prime}=0 \\
\dot{p}^{\prime}=0 \\
\dot{\sigma}_{z}^{\prime}=0\end{array}$ & 100 & $3 \cdot 3,6 \cdot 25,16 \cdot 7,200$ & Always active \\
\hline
\end{tabular}




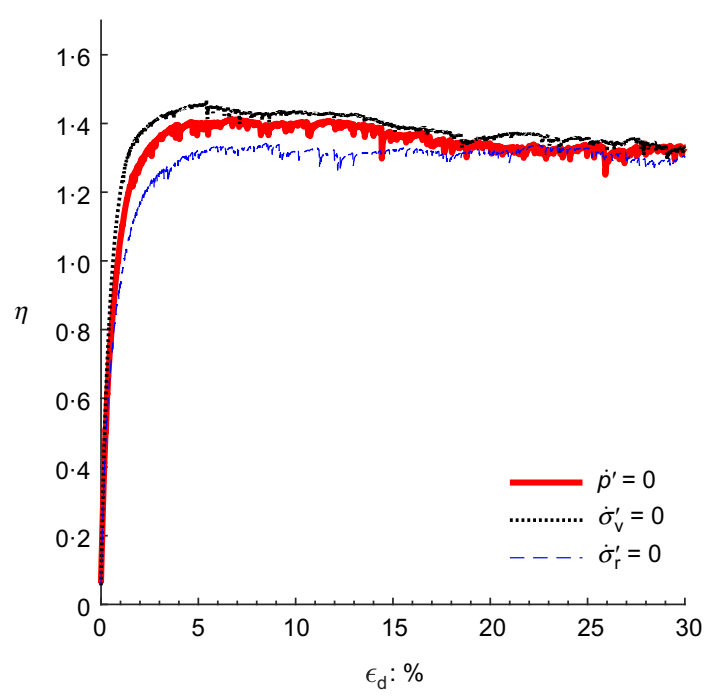

(a)

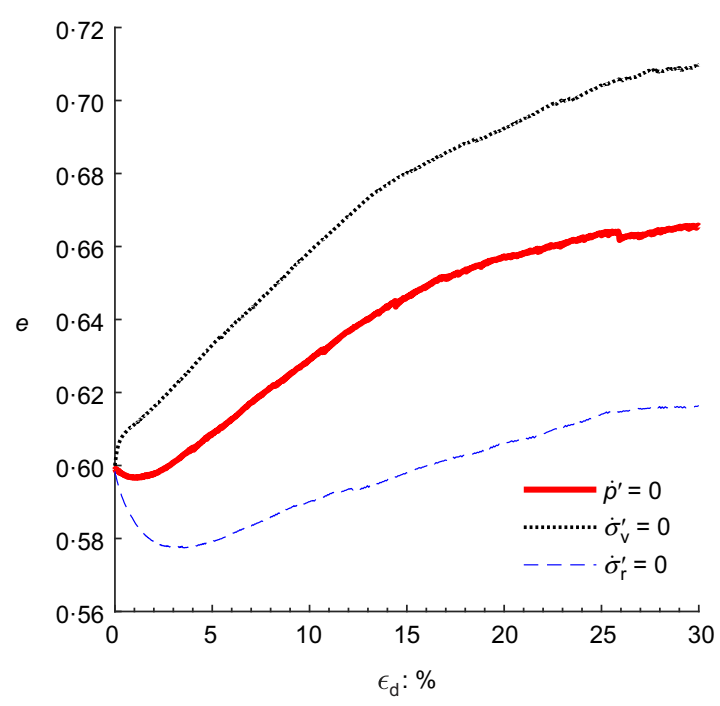

(b)

Fig. 7. Responses observed on three representative tests from simulation series A (crushable material; OCR $=1$, initial confining pressure = $6 \mathrm{MPa}$ ): (a) mobilised strength; (b) void ratio plotted against deviatoric strain for the three triaxial tests

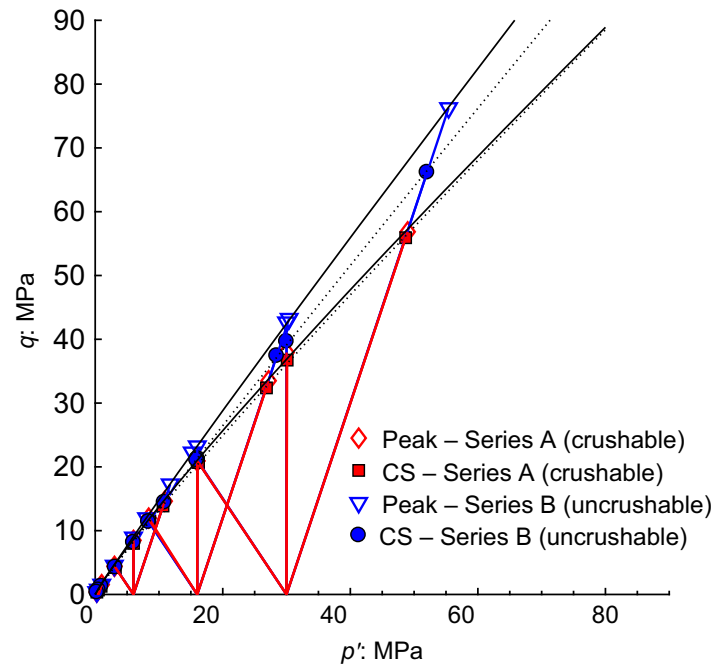

(a)

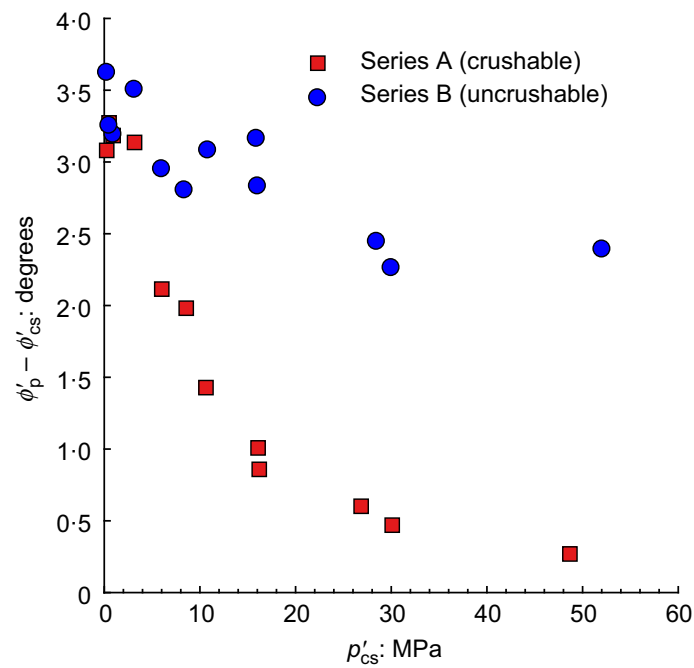

(b)

Fig. 8. Test series A (crushable material; $O C R=1$ ) and B (uncrushable material; $O C R=1$ ): (a) peak and critical state envelopes; (b) stress dilatancy angle of shearing resistance $\left(\phi_{\mathrm{p}}^{\prime}-\phi_{\mathrm{cs}}^{\prime}\right)$ plotted against mean stress at critical state

end points of the shearing paths are used to delineate a tentative CSL for both crushable and uncrushable materials. For the uncrushable case the isotropic compression line (ICL) and the CSL seem to converge at large pressures. For the crushable case, the two lines intersect each other and later become approximately parallel, a feature also observed in experiments on crushable sands (e.g. Coop \& Airey, 2003). For the uncrushable case, the CSL remains above the ICL and all tests dilate to achieve a critical state; for the crushable case the material dilates at low pressure and contracts at high pressure to reach a critical state. Similar observations are reported in previous DEM studies of this issue (Cheng et al., 2005; Hanley et al., 2015). This qualitative agreement is particularly interesting because these previous DEM models had different bases: Cheng et al. (2005) used crushable aggregates; Hanley et al. (2015) used free-rotating particles.

\section{Crushing and grading evolution}

The model has the ability to track the grading index. A projection of the data onto the $\log p^{\prime}-I_{\mathrm{G}}$ axes is given in
Fig. 10(a), illustrating both ICLs and the shearing paths towards critical states. For test series A, at a given $p^{\prime}$, the $I_{\mathrm{G}}$ data at the critical state lie above the ICL $I_{\mathrm{G}}$ values, indicating shear enhanced crushing. The amount of shear-induced crushing appears to be linked to $p^{\prime}$. There is no change in $I_{\mathrm{G}}$ for shearing paths starting well below isotropic yield (defined as the point where $I_{\mathrm{G}}$ starts increasing on the isotropic path).

By projecting the data onto the $e-I_{\mathrm{G}}$ plane in Fig. 10(b), it becomes apparent that, for this initially medium dense sand, there is dilation during shear as long as changes in grading are moderate (i.e. $\Delta I_{\mathrm{G}}<0.022$ ), whereas shear-induced contraction is indicative of a larger grading evolution. Fig. 10(c) presents a three-dimensional view of the ICL in $e-\log p^{\prime}-I_{\mathrm{G}}$ space, along with the shearing paths towards critical state; when viewed from this perspective the CSL for the crushable soil does not cross the ICL, but rather rotates or curls around it.

\section{Critical state lines at fixed grading}

In Fig. 11(a) the results of test series B, C and D (where crushing was disabled during shearing) are presented 


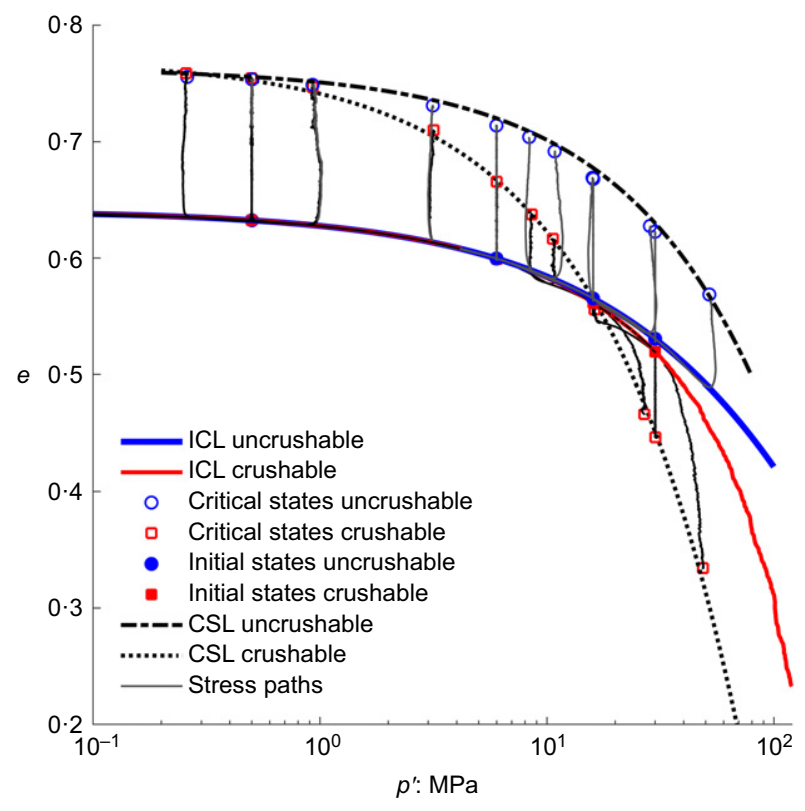

Fig. 9. Crushable as opposed to uncrushable critical state investigation: response in the compression plane

in $e-\log p^{\prime}-I_{\mathrm{G}}$ space. For these tests shearing occurred at constant $I_{\mathrm{G}}$ and it is clear that the critical states of series B $\left(I_{\mathrm{G}}=0.737\right)$ lie above those of test series C $\left(I_{\mathrm{G}}=0.779\right)$, which in turn lie above those of test series $\mathrm{D}\left(I_{\mathrm{G}}=0 \cdot 820\right)$. This ordering is emphasised in the projection onto the $e-\log$ $p^{\prime}$ plane (Fig. 11(b)).

In Fig. 12 three CSLs are fitted to the critical state points attained in the simulations with constant $I_{\mathrm{G}}$ using the following expression

$$
e_{\mathrm{c}}=\Gamma+\gamma\left(\frac{p^{\prime}}{p_{\mathrm{a}}}\right)^{0 \cdot 7}
$$

Normalisation of the isotropic stress axis follows Li \& Wang (1998) and $p_{\mathrm{a}}$ is the atmospheric pressure, taken as $101 \mathrm{kPa}$ here. Very good fits are obtained $\left(R^{2}>0.99\right.$ in all cases). The empirical normalisation exponent of 0.7 which is recovered here was also recovered by Hanley et al. (2015). It is interesting to note that this was not the case in other DEM studies of critical state (Yan \& Dong, 2011; Li et al., 2015), where a larger exponent ( $0 \cdot 9)$ was reported. This discrepancy may be due to differences in the contact model. Authors who obtained larger normalising exponents used linear elastic models, whereas both here and in Hanley et al. (2015) a Hertz-Mindlin elastic contact was used. In the Hertz-Mindlin formulation, incremental contact stiffness scales with a factor $p^{1 / 3}$ and thus secant stiffness varies with a factor $p^{2 / 3}$. This is a value quite close to the 0.7 observed for the whole ensemble at critical state.

The offset CSLs all have very similar slopes $(\gamma)$; each within $3 \%$ of the mean value (Table 4, Fig. 12), but a systematic slight reduction in $\gamma$ with increasing $I_{\mathrm{G}}$ is evident. This trend is in agreement with Muir Wood \& Maeda (2008) and Li et al. (2015). The CSLs obtained at constant grading will be subsequently referred to as $\mathrm{CSL}_{I_{\mathrm{G}-} x} \mathrm{CSL}_{\mathrm{IG}_{-} x}$, where subscript $x$ gives the relevant $I_{\mathrm{G}}$ value.

As the three CSLs obtained with different gradings are almost parallel, a single plane can be tightly fitted in the three-dimensional space that includes the grading index, Fig. 13. The equation of this CSP is

$$
e_{\mathrm{c}}=\alpha+\beta I_{\mathrm{G}}+\delta\left(\frac{p^{\prime}}{p_{\mathrm{a}}}\right)^{0.7}
$$

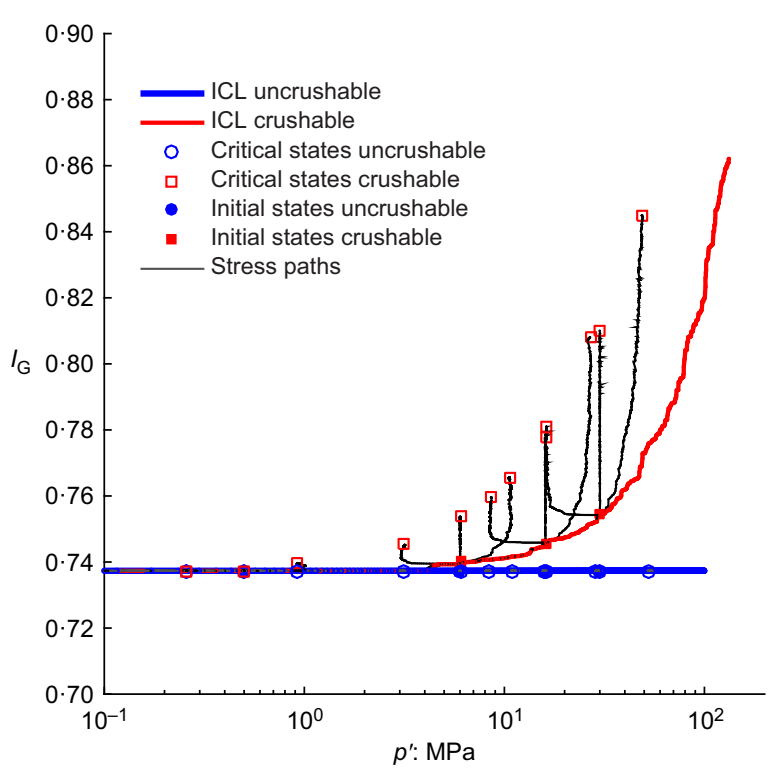

(a)

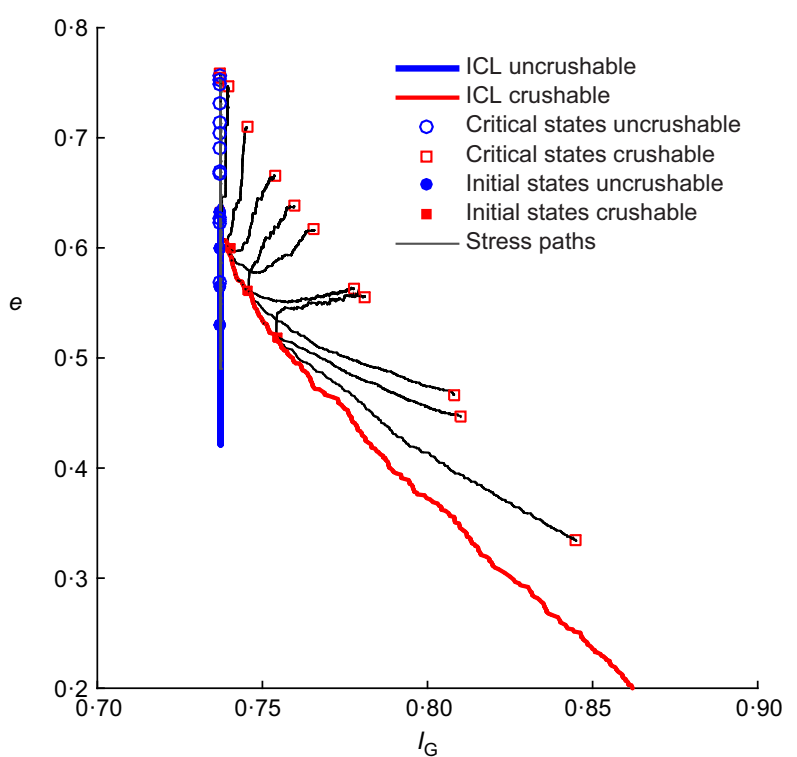

(b)

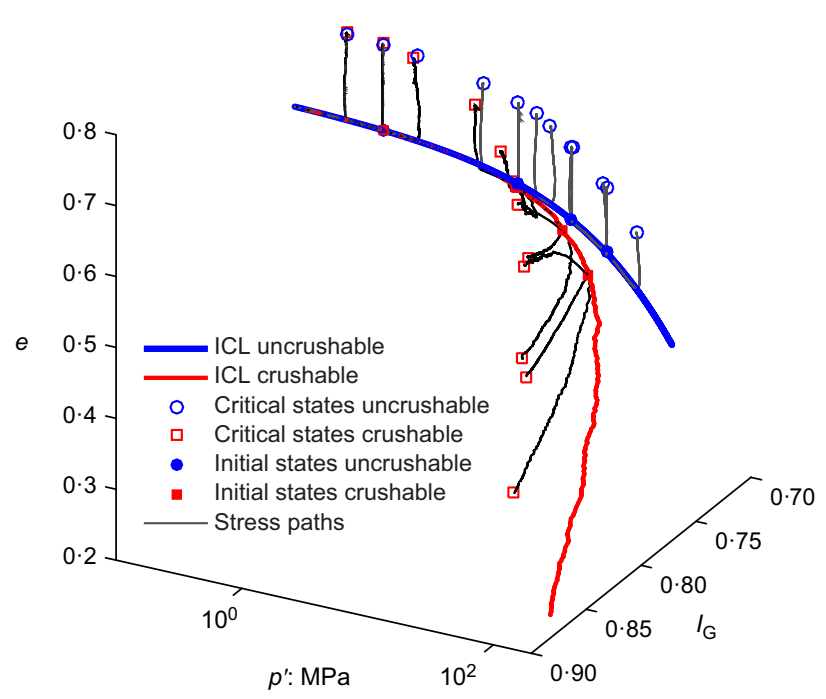

(c)

Fig. 10. Crushable and uncrushable critical state investigation: (a) state evolution in $\log p^{\prime}-I_{\mathrm{G}}$ plane; (b) state evolution in $I_{\mathrm{G}}-e$ plane; (c) state evolution in $e-\log p^{\prime}-I_{\mathrm{G}}$ space 


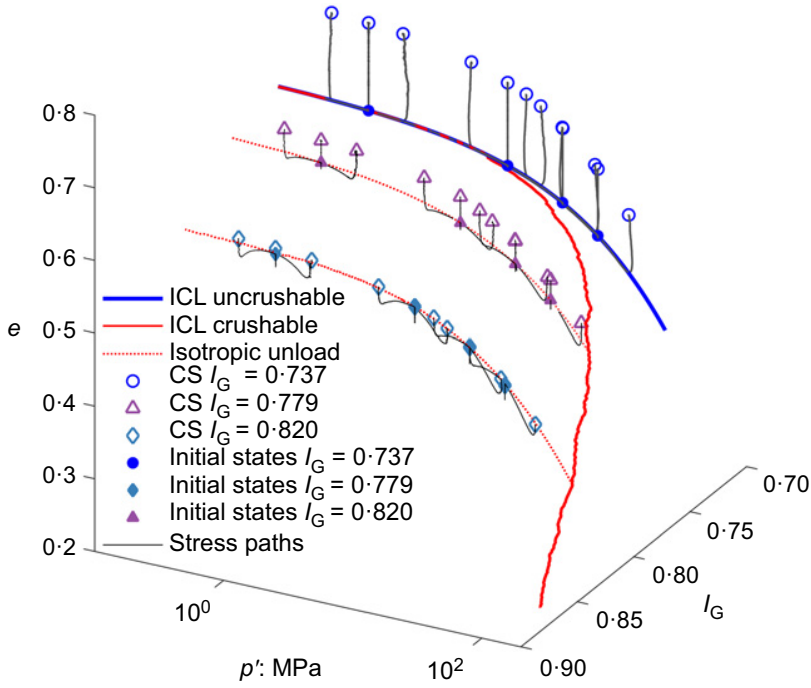

(a)

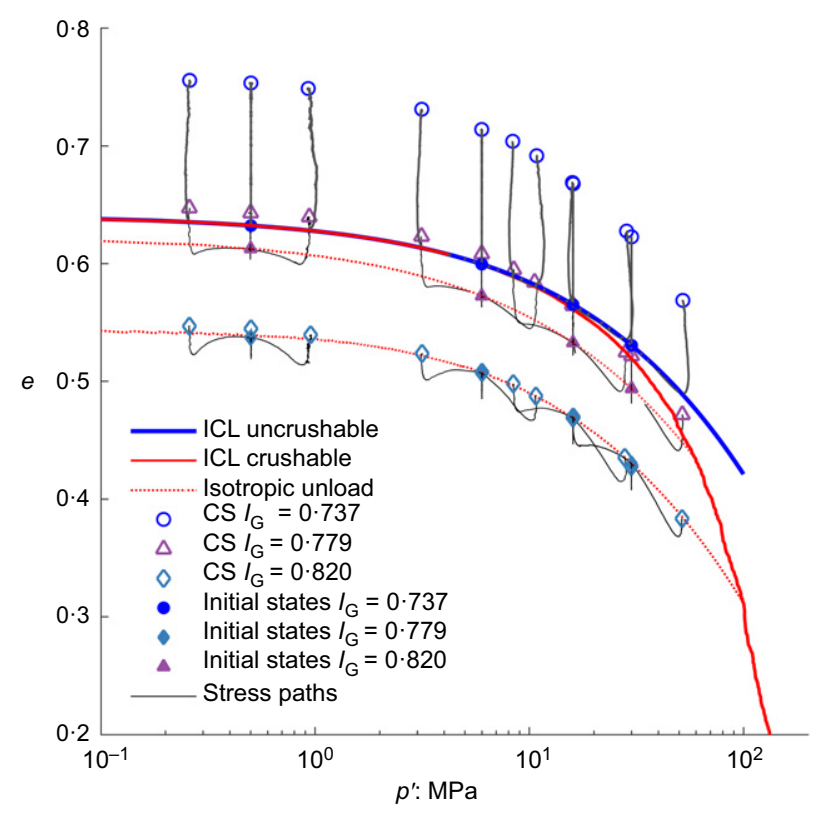

(b)

Fig. 11. (a) State evolution in $e-\log p^{\prime}-I_{\mathrm{G}}$ space including two unload paths and stress paths of other 24 shear tests to critical state where crushing is inhibited; (b) corresponding two-dimensional plot in $\log p^{\prime}-I_{G}$ plane

where the fitting parameters $\alpha, \beta$ and $\delta$ were obtained by least-squares regression to be $\alpha=2.553, \beta=-2.441$ and $\delta=-2 \cdot 325 \times 10^{-3}$. As expected, the fit is as good as those of the individual $\mathrm{CSL}_{I_{\mathrm{G}} \times}\left(R^{2}>0.99\right)$.

In the DEM simulations, stresses were applied by way of rigid walls; the resultant regions of lower density which are present close to the rigid walls may affect the evaluation of a representative void ratio and hence the location of the CSL (Huang et al., 2014b). To assess the sensitivity of the results to this issue, the $\mathrm{CSL}_{I_{\mathrm{G}} 0.737}$ was determined twice, once by deducing $e$ from the boundary displacements of the cubic cell and then by tracking porosity of an internal measurement sphere (centred in the cell, with radius equal to the cubic cell side minus $d_{50}$ ). The two CSLs are illustrated in Fig. 12 and it is clear that the effect was small (the $e$ values consistently varied by $2-3 \%$ ) and so the volume values obtained from boundary measurements are considered for all results reported here.

\section{Critical states with evolving grading}

In laboratory conditions, crushing cannot be switched off at will. The CSLs of soils on the crushable range are typically identified (e.g. Coop \& Lee, 1993) by joining points at different stages of grading evolution. The same procedure is applied here using the test results from series A, which correspond to a normally consolidated crushable material. Regression analysis was used to obtain the parameters for equation (6); the resultant parameter values are reported in Table 4 and the data points and fitted line are presented in Fig. 12. This CSL at variable grading, which will be denoted $\mathrm{CSL}_{\mathrm{nc}}$, has a much steeper gradient than the $\mathrm{CSL}_{I_{\mathrm{G}-} x}$ obtained at fixed gradings. As detailed in the Appendix, this is true even allowing for a slight overestimation $(5 \%)$ of this gradient induced by the volume loss allowed in the simulations.

In Fig. 13 the $\mathrm{CSL}_{\mathrm{nc}}$ identified in tests with variable grading is plotted alongside the CSP previously identified by testing at fixed gradings. The relation between both sets of data is clearer in Fig. 14, which shows that the CSP equation - determined with tests sheared at fixed

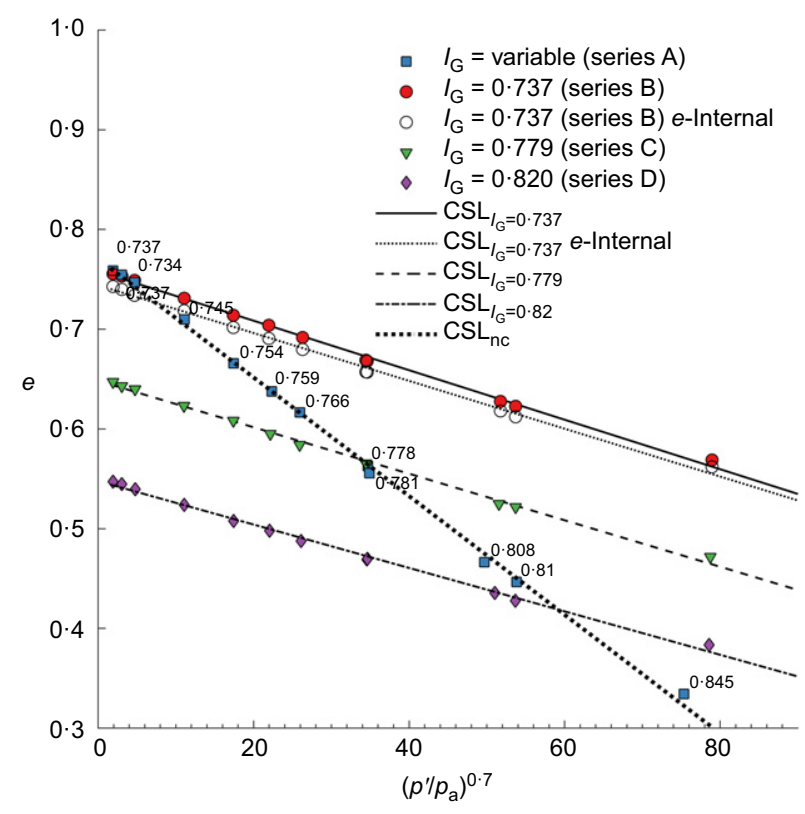

Fig. 12. Critical state lines for the Fontainebleau sand analogue at fixed and variable grading. $e$-Internal refers to the internal measurement sphere results

grading - predicts very well the critical state void ratio attained while shearing at variable grading. Therefore, the $\mathrm{CSL}_{\mathrm{nc}}$ is contained within the CSP.

The CSP is a better descriptor of the material behaviour than the $\mathrm{CSL}_{\mathrm{nc}}$. This is demonstrated by observing the critical state points attained by a crushable material shearing from overconsolidated states; the results of test series E and F. Fig. 15 presents the critical state points obtained from these tests as well as the previously defined CSLs. The critical state points of series $\mathrm{E}$ and $\mathrm{F}$ do not lie on the $\mathrm{CSL}_{\mathrm{nc}}$. However, all tests, without exception, attain critical state at points very close to the CSP (Fig. 14). The figure also includes data from the experimental results reported previously in Fig. 5. The experimental critical state conditions fit very well those 
Table 4. Critical state lines (equation (6): $e_{\mathrm{c}}=\Gamma+\gamma\left(p^{\prime} \mid p_{\mathrm{a}}\right)^{0 \cdot 7}$ ) for different grading of the FS analogue

\begin{tabular}{l|l|c|c|c}
\hline Test series & Grading index & $\Gamma$ & $\gamma$ & Coefficient of determination, $R^{2}$ \\
\hline A & Variable & 0.771 & $5.949 \times 10^{-3}$ & 0.99 \\
B & 0.737 & 0.758 & $2.482 \times 10^{-3}$ & 0.99 \\
C & $0 \cdot 779$ & 0.648 & $2.399 \times 10^{-3}$ & 0.99 \\
D & 0.820 & 0.548 & $2.331 \times 10^{-3}$ & 0.99 \\
\hline
\end{tabular}

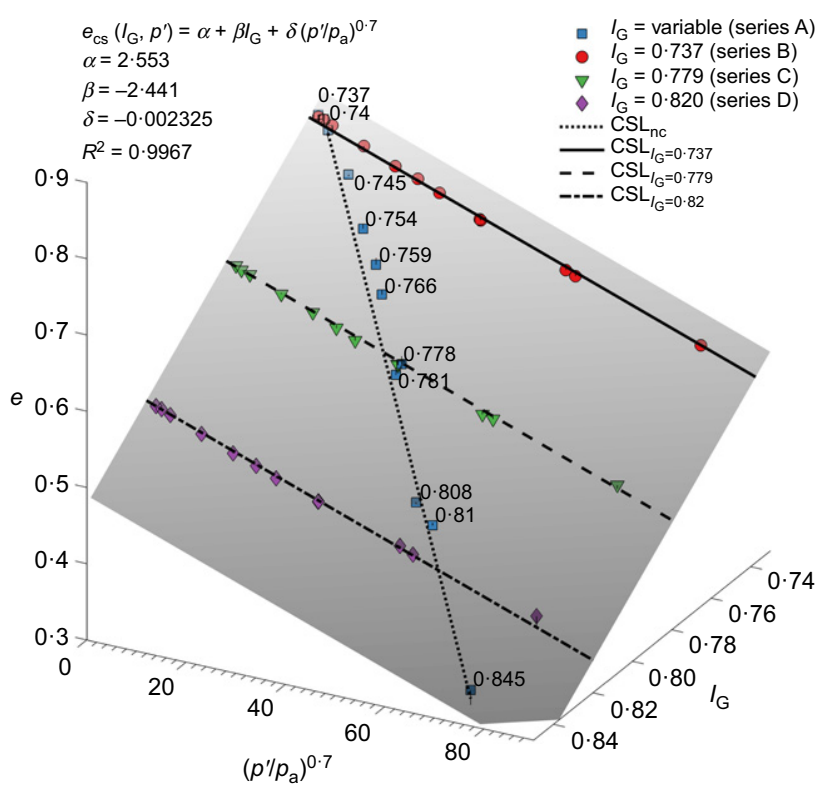

Fig. 13. Definition of CSP as a function of $I_{\mathrm{G}}-e-p^{\prime}$

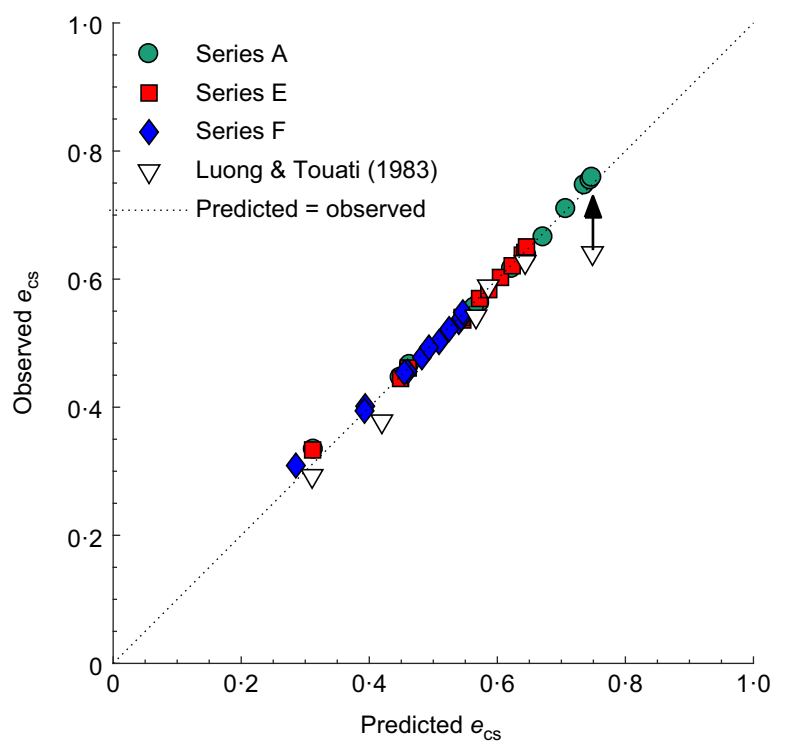

Fig. 14. Critical state values for evolving grading: predicted values from the CSP plotted against observed values

predicted by the numerical CSP; the only exception corresponds to the test performed at $0.5 \mathrm{MPa}$, which at failure was still dilating and had not reached the critical state (Fig. 5(a)).

\section{Overconsolidation and yield in crushing}

Referring to Fig. 15 the test data from series $\mathrm{E}$ and $\mathrm{F}$ each trace a curve that, at low overconsolidation ratio (OCR), converges to the $\mathrm{CSL}_{\mathrm{nc}}$, and, at high $\mathrm{OCR}$, agrees with the

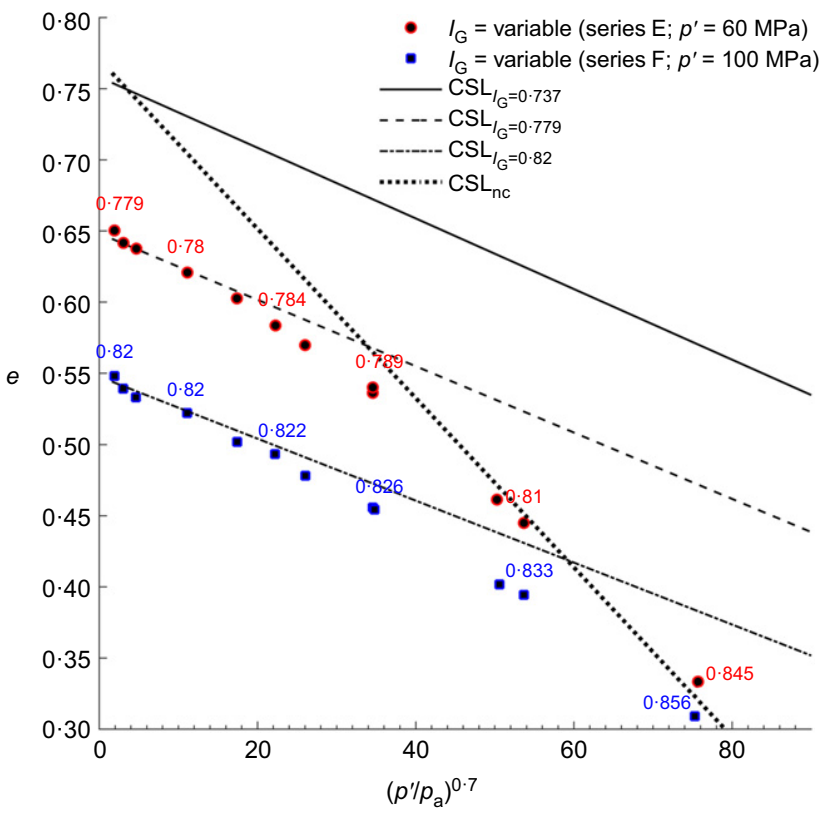

Fig. 15. CSL for fixed and variable grading and critical state points obtained in overconsolidated crushable material (test series $\mathbf{E}$ and $F$ ). Labels indicate values of $I_{G}$ in chosen points

previously established CSLs obtained at constant grading. These asymptotes at high $\mathrm{OCR}$ are, respectively, $\mathrm{CSL}_{I_{\mathrm{G} \_} 0.779}$ for series $\mathrm{E}$ and $\mathrm{CSL}_{I_{\mathrm{G} \_} 0.820}$ for series $\mathrm{F}$. These are the CSLs obtained by fixing grading at the $I_{\mathrm{G}}$ level attained just before unloading.

It appears then that the $I_{\mathrm{G}}$ value obtained during precompression is only relevant for the more highly overconsolidated specimens. Following the terminology of Bandini \& Coop (2011), one could talk of a 'memory' of grading slowly reappearing upon unloading. Actually, a clearer explanation of this phenomenon requires a more general consideration of the grading evolution pattern in the stress plane.

Figure 16(a) shows how grading evolves with $p^{\prime}$ during compression tests at constant stress obliquity $\eta=q / p^{\prime}$ taken up to $p^{\prime}=120 \mathrm{MPa}$. The largest stress obliquity for these tests $(\eta=1 \cdot 2)$ is close to, but still below, that estimated for the CSL (see Fig. 5(f) and related discussion in the Appendix). These test data were used to develop the $I_{\mathrm{G}}$ contour plot in the plane $p^{\prime}-q$ presented in Fig. 16(b). The shapes of these curves resemble the theoretical yield curves for the crushing plastic mechanism postulated by Kikumoto et al. (2010) in their two-mechanism elasto-plastic model. When a crushing-type yield takes place, the mechanism is activated and $I_{\mathrm{G}}$ changes. Changes in $I_{\mathrm{G}}$ change the position of the relevant CSL within the CSP.

The shearing stress paths from test series $\mathrm{E}$ are overlain on the $I_{\mathrm{G}}$ contour plot (where the $I_{\mathrm{G}}=0.779$ contour has been highlighted) in Fig. 17. The stress paths starting at $p^{\prime}=5 \mathrm{MPa}(\mathrm{OCR}=10)$ do not cross the $I_{\mathrm{G}}=0.779$ contour until they are close to the critical state. For these 


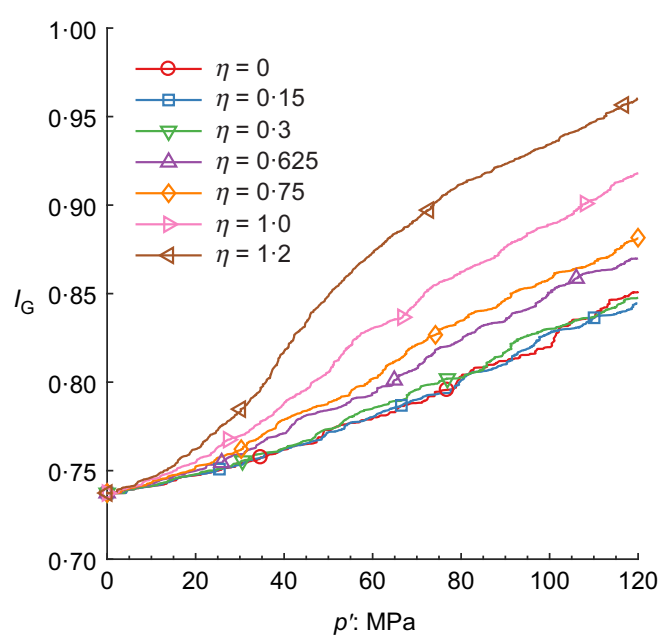

(a)

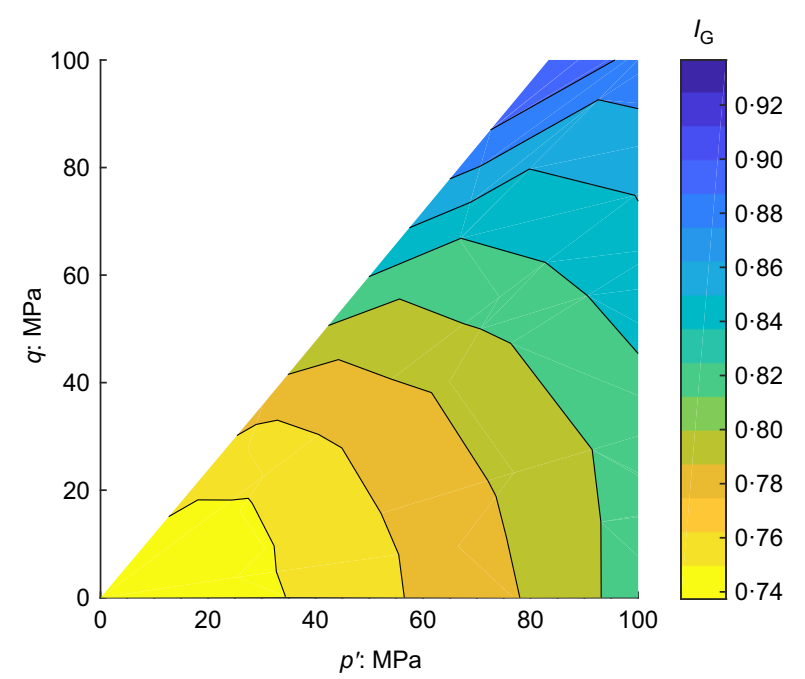

(b)

Fig. 16. (a) Grading evolution during tests at fixed stress obliquity $\eta=q I p^{\prime}$; (b) corresponding iso- $I_{G}$ map

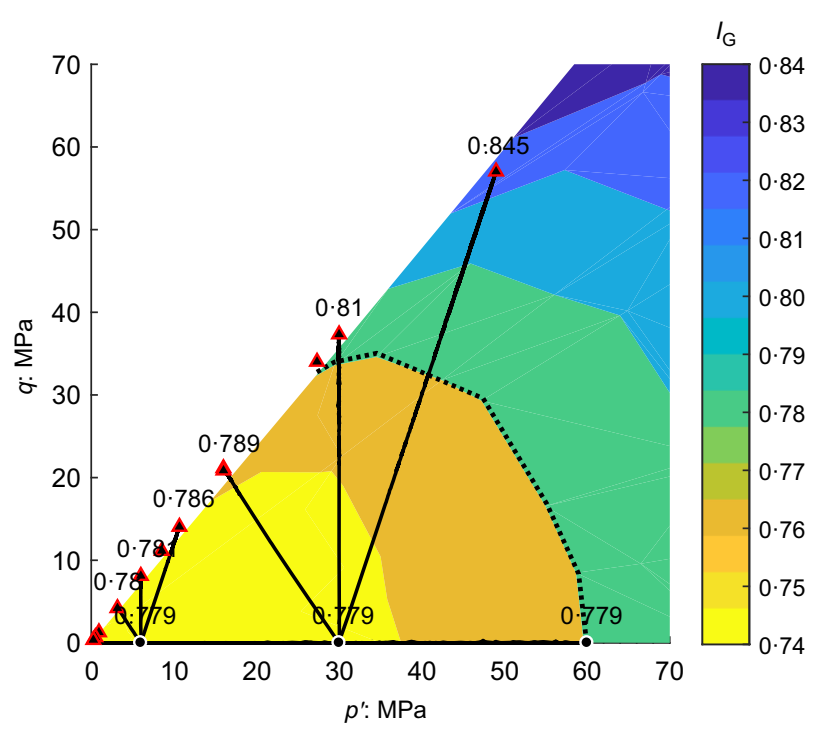

Fig. 17. Stress paths of $\mathrm{OC}$ samples (test series $\mathrm{E}$ ) superimposed on the iso- $I_{\mathrm{G}}$ map

cases, the relevant CSL in the compression plane is the $\mathrm{CSL}_{I_{\mathrm{G}-} 0.779}$. However, the paths starting at $p^{\prime}=30 \mathrm{MPa}$ $(\mathrm{OCR}=2)$ do cross the $I_{\mathrm{G}}=0 \cdot 779$ contour well before critical state is attained. Grading evolves before critical state is attained and the location of the CSL in the compression plane varies during shearing.

\section{DISCUSSION}

\section{Comparison with other granular materials}

The results presented have significant practical implications for experimental studies. The same experimental data used to obtain a $\mathrm{CSL}_{\mathrm{nc}}$ may be used to fit a CSP, with more general validity. The extra data requirements are: $(a)$ to supplement each critical state data point with information about the final grading; $(b)$ to collect enough data points to fit three parameters instead of two. CSP identification for two other published datasets is now illustrated, giving some context to the numerically obtained values for the CSP of FS.
Xiao et al. (2016) identified a CSP for Tacheng rockfill, but they quantified the grading evolution using a different measure to $I_{\mathrm{G}}$. Their data can be reinterpreted - using the grading index $I_{\mathrm{G}}$ - to fit equation (7); the resultant CSP is illustrated in Fig. 18(a). The CSP obtained for the carbonate Dogs Bay sand data reported by Coop \& Lee (1993) and Bandini \& Coop (2011) is illustrated in Fig. 18(b). These CSPs can be directly compared with the DEM FS data in Fig. 13. The $\alpha, \beta$ and $\delta$ defining each CSP are listed in Table 5; these data show that the effect of grading on critical states, given by the coefficient $\beta$, is smaller for FS than for the Dogs Bay carbonate sand and higher than for the Tacheng rockfill. This may be related to the different ranges of void ratios that are attainable for these very different granular materials.

\section{Micromechanical observations}

A detailed analysis of the micromechanical features of the relation between critical states and grading is beyond the scope of the present work. As a first step in that direction, the mechanical coordination number $Z^{m}$ at critical state conditions was examined. $Z^{m}$ was defined by Thornton (2000) as the coordination number computed after particles with only one or two contacts are excluded from the count. $Z^{m}$ has been extensively used in subsequent studies, for example Hanley et al. (2015).

In Fig. 19(a) $Z^{m}$ is plotted against the void ratio at CS for all tests in series A to F. It appears that there is a one-on-one relation between the two variables only if grading is kept constant. Soils with higher $I_{\mathrm{G}}$ (i.e. those with more evolved and less uniform grading) attain a denser critical state condition for the same value of mechanical coordination number. Interestingly, results from the $\mathrm{NC}$ series A cut across the different constant $I_{\mathrm{G}}$ curves, whereas results from the $\mathrm{OC}$ series $\mathrm{E}$ and $\mathrm{F}$ bridge the $\mathrm{NC}$ and constant $I_{\mathrm{G}}$ curves. This pattern is very similar to that observed in the compression plane (Fig. 12).

The reason for that similar pattern is apparent on Fig. 19(b), which presents the relation between confining pressure and mechanical coordination number at critical state. It appears that this relation is independent of grading, and is the same for all test series. Similar relations between $p^{\prime}$ and $Z^{m}$ at critical state have been reported previously (Gu et al., 2014; Huang et al., 2014a; Nguyen et al., 2017), although it was never noted that the relation was grading-independent. 


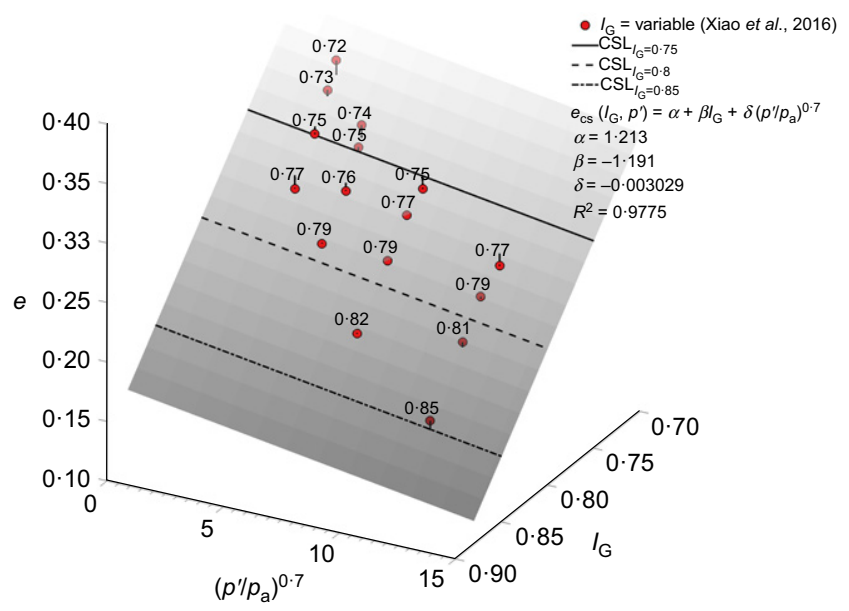

(a)

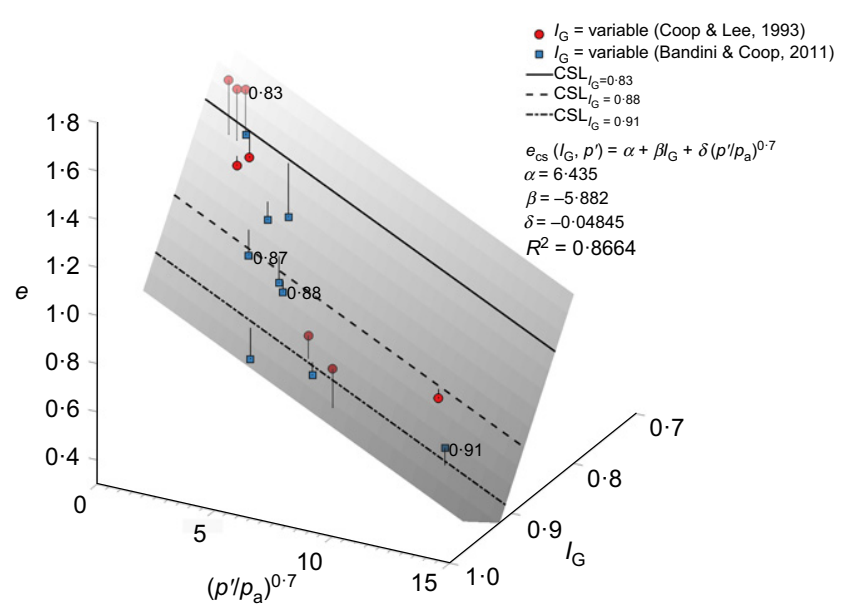

(b)

Fig. 18. Critical state planes for various materials. Data labels indicate values of $\boldsymbol{I}_{\mathrm{G}}$ for some selected points: (a) Tacheng rockfill (reinterpreted from Xiao et al. (2016)); (b) Dogs Bay sand (reinterpreted from Coop \& Lee (1993) and Bandini \& Coop (2011))

Table 5. Critical state plane parameters (equation (7): $\left.e_{\mathrm{c}}=\alpha+\beta I_{\mathrm{G}}+\delta\left(p^{\prime} \mid p_{\mathrm{a}}\right)^{0 \cdot 7}\right)$ for different materials

\begin{tabular}{l|l|c|r|r|r}
\hline Material & Source & $\alpha$ & $\beta$ & $\delta$ & $R^{2}$ \\
\hline FS analogue & Present study & $2 \cdot 55$ & $-2 \cdot 44$ & $-0 \cdot 0023$ & $0 \cdot 99$ \\
Dogs Bay sand & Coop \& Lee (1993); Bandini \& Coop (2011) & $6 \cdot 43$ & $-5 \cdot 88$ & $-0 \cdot 0048$ & $0 \cdot 86$ \\
Tacheng rockfill & Xiao et al. (2016) & $1 \cdot 21$ & $-1 \cdot 19$ & $-0 \cdot 0030$ & $0 \cdot 97$ \\
\hline
\end{tabular}

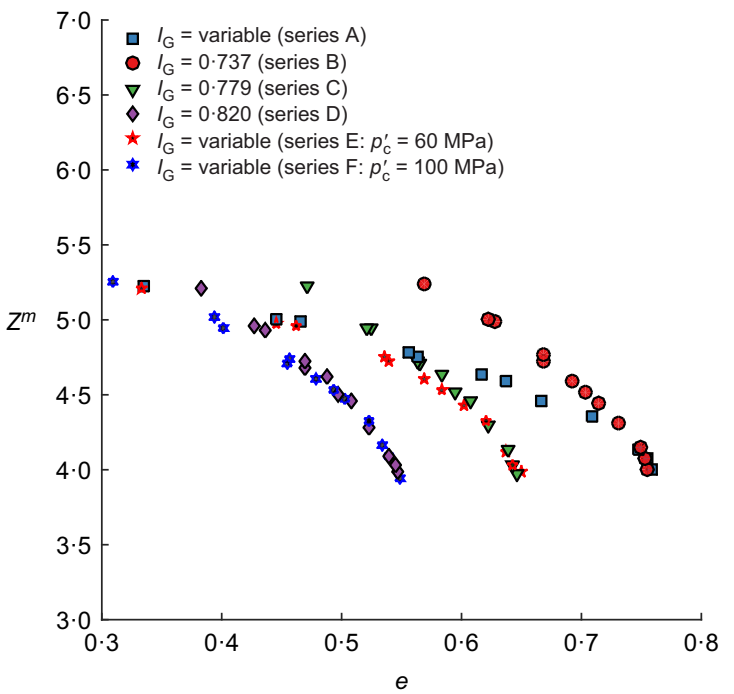

(a)

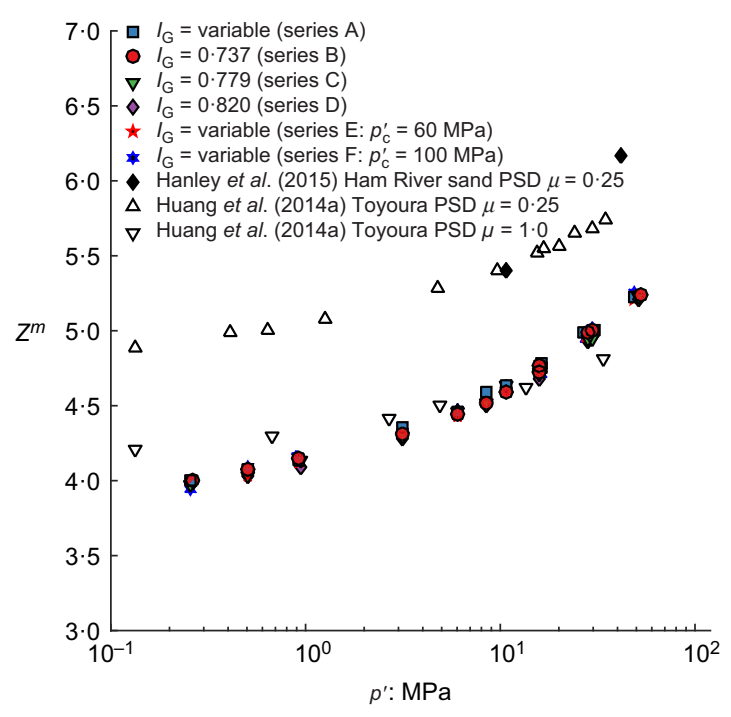

(b)

Fig. 19. Relation between mechanical coordination number $Z^{m}$ at critical state: (a) void ratio at critical state; (b) mean effective pressure at critical state

The $p^{\prime}$ plotted against $Z^{m}$ relation is known to be sensitive to contact model and particle-scale characteristics, such as inter-particle friction (Huang et al., 2014a). As shown in Fig. 19(b), the results obtained here plot closer to those obtained by Huang et al. (2014a) wherein inter-particle friction value was set at 1 , instead of those obtained with a value similar to the one employed here $(\mu=0 \cdot 25)$. The difference is likely due to the inhibition of particle rotation. The equivalence of high inter-particle friction and blocked rotation in this respect should not be taken too far: high inter-particle friction values are unable to increase macroscopic friction and have other undesirable side effects (Huang et al., 2014a).

\section{CONCLUSIONS}

The discrete model employed here offers a novel combination of numerical efficiency and grading tracking capabilities. This has enabled systematic exploration and clarification of a number of questions related to critical states. The results obtained support the hypothesis of a multiplicity of CSLs in the compression plane for crushable granular materials. They also clarify how those lines are related to grading. If grading is fixed practically parallel CSLs are obtained. These lines shift downwards as grading evolves towards the fractal limit and they all belong in a CSP. That CSP also includes the classically identified $\mathrm{CSL}_{\mathrm{nc}}$, which 


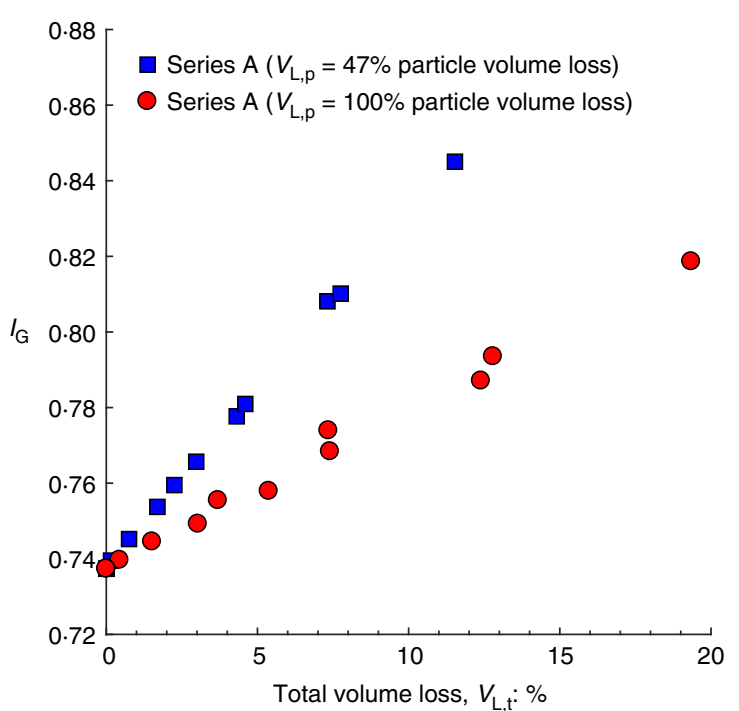

Fig. 20. Cumulative volume loss plotted against $I_{G}$ for tests in series $A$

strictly only pertains to the normally consolidated material. At low values of OCR, the difference between the observed critical states and those attained from the $\mathrm{CSL}_{\mathrm{nc}}$ is small, since the shearing path towards critical state involves renewed crushing. At high values of OCR the material attains critical states that are linked to the grading attained during previous compression.

Grading evolution may be present in some geotechnical applications, particularly those involving intense preloading of a crushable material. A systematic consideration of grading evolution and its consequences is helpful in extending critical state soil mechanics principles to those cases. In this respect, it is encouraging that the observed changes on CSLs are in agreement with the hypothesis advanced in elasto-plastic continuum models for crushable soils, such as Kikumoto et al. (2010). Other continuum modelling approaches (e.g. Tengattini et al., 2016) may also draw support from the results presented.

\section{ACKNOWLEDGEMENTS}

This research was primarily supported by the first author's Junior Research Fellowship at Imperial College and by the Spanish Ministry of Economy through grant (BIA2014-59467-R). The support provided by the EU-funded GEO-RAMP RISE project (H2020-645665GEO-RAMP) is also acknowledged.

\section{APPENDIX. SENSITIVITY OF RESULTS TO MASS LOSS EFFECTS}

In the discrete model used here, solid volume is not conserved. When a particle breaks, its volume is only partly replaced by that of the spawned fragments. For the simulations presented in each breakage event there is a loss of $47 \%$ of the particle volume, $V_{\mathrm{L}, \mathrm{p}}$. This value of $V_{\mathrm{L}, \mathrm{p}}$ was judged to be small based on previous parametric studies of this modelling approach (Ciantia et al., 2015; 2016b). Nevertheless, work by Hanley et al. (2015) indicates that at high pressures a lack of volume conservation may decrease the critical state friction angle and, more importantly for the current study, increase volumetric deformation. Consequently, the significance of volume loss for the data presented here was considered.

Most particles do not break and $V_{\mathrm{L}, \mathrm{p}}$, the particle volume loss in a single breakage event, is very small relative to the specimen volume. For a given value of $V_{\mathrm{L}, \mathrm{p}}$ (determined by the spawning fragment configuration) the total volume loss $\left(V_{\mathrm{L}, \mathrm{t}}\right)$ attained in a test is directly proportional to the number of crushing events and therefore to the $I_{\mathrm{G}}$ attained (Fig. 20).

For test series $\mathrm{B}, \mathrm{C}$ and $\mathrm{D}, I_{\mathrm{G}}$ does not change during shearing and so the slopes of the $\mathrm{CSL}_{\mathrm{IG}_{-} x}$ lines presented in Fig. 12 are insensitive to $V_{\mathrm{L}, \mathrm{p}}$ because the error induced during the isotropic compression phase is equal for all tests in the series. $I_{\mathrm{G}}$ varies most significantly in test series $\mathrm{A}$; therefore, to gauge the importance of this effect, all tests from series A were repeated, but now removing particles at breakage - that is, having $V_{\mathrm{L}, \mathrm{p}}=100 \%$ rather than $V_{\mathrm{L}, \mathrm{p}}=47 \%$ as for the standard 14-particle spawning procedure. The results, shown in Fig. 21, confirm the two effects of volume loss indicated by Hanley et al. (2015): (a) volume loss measurably reduces the critical state friction angle; $(b)$ volume loss decreases the void ratio attained at critical state.

The effect on void ratio is the more important here, since it increases the CSL slopes. To quantify the bias, test series A was again repeated for several values of break volume loss, $V_{\mathrm{L}, \mathrm{p}}$, ranging between $V_{\mathrm{L}, \mathrm{p}}=47 \%$ and $V_{\mathrm{L}, \mathrm{p}}=100 \%$. A CSL $\mathrm{CH}_{\mathrm{nc}}$ was fitted in each case (Fig. 22(a)) in $e-p^{\prime}$ space. The dependence of the resultant CSL slopes on the particle volume loss in breakage is shown in Fig. 22(b). Extrapolation of the observed trend indicates that the error introduced in the slope estimate by the default break volume loss assumption is about $5 \%$.

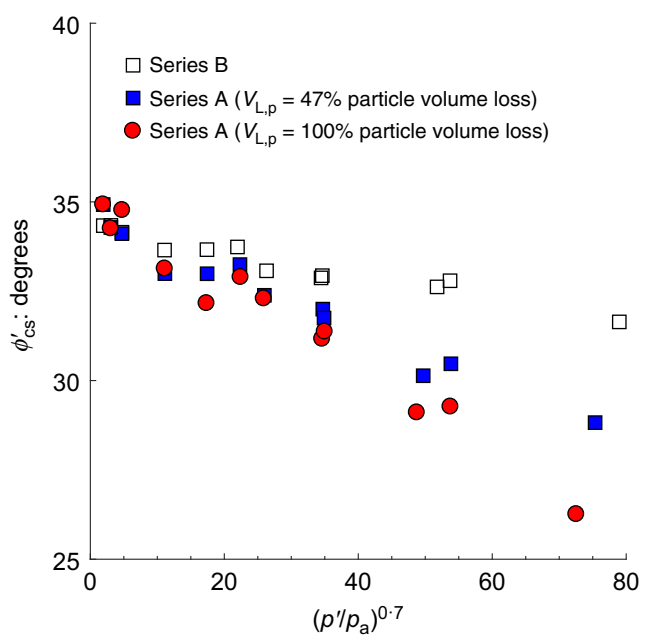

(a)

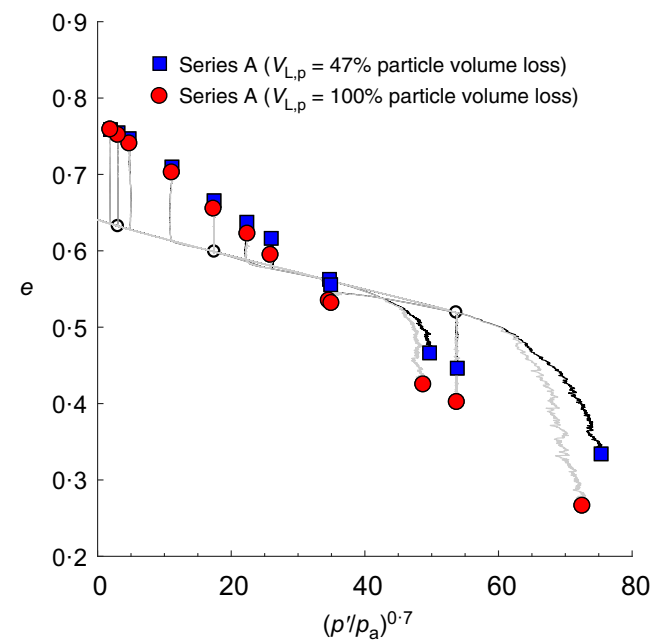

(b)

Fig. 21. Effect of break volume loss on critical state features: (a) friction angle; (b) critical state void ratio 


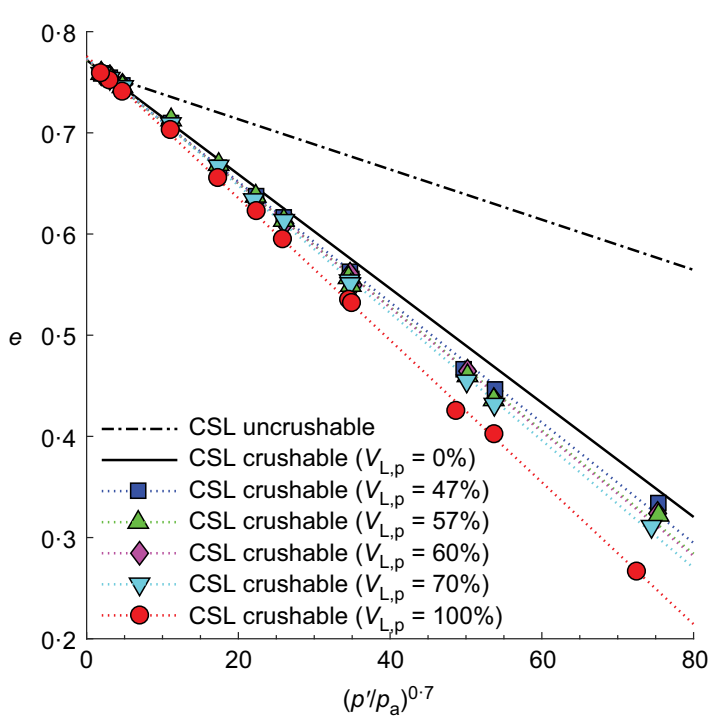

(a)

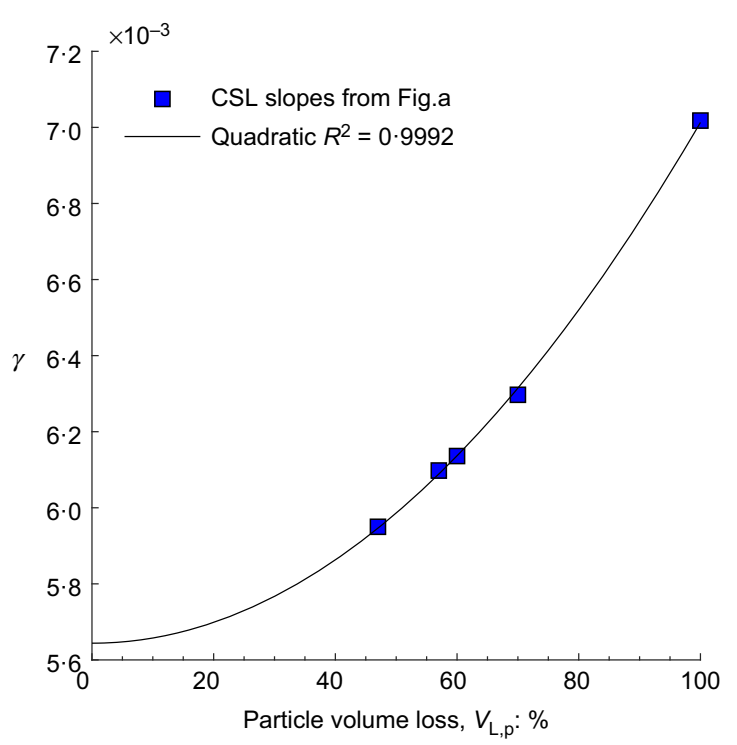

(b)

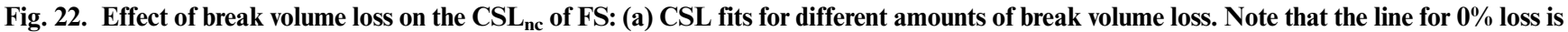
extrapolated according to (b) relation between break volume loss and CSL slope

\section{NOTATION}

$A_{\mathrm{F}}$ contact area

$d$ diameter of sphere

$d_{\max }$ maximum particle size assumed for the limit distribution

$d_{\text {min }}$ minimum particle size assumed for the limit distribution

$d_{0}$ reference diameter of sphere

$E_{1}, E_{2} \quad$ Young's moduli of particle

e void ratio

$e_{\mathrm{c}}$ void ratio at critical state

$F$ force at particle contact

$F_{\text {lim }}$ limit contact force

$f$ (var) effect of variability of particle strength

$I_{\mathrm{G}}$ grading state index

$M_{(L<d)} \quad$ mass of particles smaller than $d$

$M_{\mathrm{T}}$ total mass

$m$ material parameter

$p^{\prime} \quad$ mean effective stress

$p_{\mathrm{a}}$ atmospheric pressure

$p_{\mathrm{c}}^{\prime} \quad$ isotropic pre-consolidation stress

$p_{0}^{\prime} \quad$ isotropic stress before shearing

$r_{1}, r_{2}$ radii of contacting spheres

$V_{\mathrm{L}, \mathrm{p}}$ particle volume loss in a single breakage event

$V_{\mathrm{L}, \mathrm{t}}$ total volume loss attained in a test

$\alpha, \beta, \delta \quad$ CSP fitting parameters

$\eta$ mobilised friction value

$\Gamma, \gamma \quad$ CSL fitting parameters

$\mu$ coefficient of inter-particle friction

$v_{1}, v_{2}$ particle Poisson ratios

$\rho_{\mathrm{s}} \quad$ specific gravity

$\sigma_{\lim }$ limit strength of material

$\bar{\sigma}_{\lim }$ mean strength for a sphere of diameter $d$

$\sigma_{\lim , 0} \quad$ mean strength for a sphere at the reference size $d_{0}$

$\phi_{\mathrm{cs}}^{\prime} \quad$ critical state friction angle

$\phi_{\mathrm{p}}^{\prime} \quad$ peak friction angle

$\psi \quad$ state parameter

$\omega$ fractal dimension of the limit grading

\section{REFERENCES}

Altuhafi, F., O'Sullivan, C. \& Cavarretta, I. (2013). Analysis of an image-based method to quantify the size and shape of sand particles. J. Geotech. Geoenviron. Engng 139, No. 8, 1290-1307.

Arroyo, M., Butlanska, J., Gens, A., Calvetti, F. \& Jamiolkowski, M. (2011). Cone penetration tests in a virtual calibration chamber. Géotechnique 61, No. 6, 525-531, https://doi.org/10.1680/ geot.9.P.067.
Azeiteiro, R. J. N., Coelho, P. A. L. F., Taborda, D. M. G. \& Grazina, J. C. D. (2017). Critical state-based interpretation of the monotonic behaviour of Hostun sand. J. Geotech. Geoenviron. Engng 143, No. 5, https://doi.org/10.1061/(ASCE) GT.1943-5606.0001659.

Bandini, V. \& Coop, M. R. (2011). The influence of particle breakage on the location of the critical state line of sands. Soils Found. 51, No. 4, 591-600.

Been, K. \& Jefferies, M. G. (1985). A state parameter for sands. Géotechnique 35, No. 2, 99-112, https://doi.org/10.1680/ geot.1985.35.2.99.

Bishop, A. W. \& Green, G. E. (1965). The influence of end restraint on the compression strength of a cohesionless soil. Géotechnique 15, No. 3, 243-266, https://doi.org/10.1680/geot.1965.15.3.243.

Calvetti, F. (2008). Discrete modelling of granular materials and geotechnical problems. Eur. J. Environ. Civ. Engng 12, No. 7-8, 951-965.

Casagrande, A. (1936). Characteristics of cohesionless soils affecting the stability of slopes and earth fills. J. Boston Soc. Civ. Engrs 23, 257-276.

Cheng, Y. P., Bolton, M. D. \& Nakata, Y. (2005). Grain crushing and critical states observed in DEM simulations. In Powders and grains, Stuttgart, Germany (eds R. García-Rojo, H. J. Herrmann and S. McNamara), pp. 1393-1397. London, UK: Taylor \& Francis Group.

Ciantia, M. O., Arroyo, M., Gens, A. \& Calvetti, F. (2014). Particle failure in DEM models of crushable soil response. In Numerical methods in geotechnical engineering (eds M. A. Hicks, R. B. J. Brinkgreve and A. Rohe), pp. 345-350. Leiden, the Netherlands: CRC Press/Balkema.

Ciantia, M., Arroyo, M., Calvetti, F. \& Gens, A. (2015). An approach to enhance efficiency of DEM modelling of soils with crushable grains. Géotechnique 65, No. 2, 91-110, https://doi.org/10.1680/geot.13.P.218.

Ciantia, M. O., Arroyo, M., Butlanska, J. \& Gens, A. (2016a). DEM modelling of cone penetration tests in a double-porosity crushable granular material. Comput. Geotech. 73, 109-127.

Ciantia, M. O., Arroyo, M., Calvetti, F. \& Gens, A. (2016b). A numerical investigation of the incremental behavior of crushable granular soils. Int. J. Numer. Analyt. Methods Geomech. 40, No. 13, 1773-1798.

Colliat-Dangus, J. L. J., Desrues, J. \& Foray, P. (1988). Triaxial testing of granular soil under elevated cell pressure, advanced triaxial testing of soil and rock. West Conshohocken, PA, USA: ASTM International.

Coop, M. R. \& Airey, D. W. (2003). Carbonate sands. In Characterisation and engineering properties of natural soils, 
Singapore (eds T. S. Tan, K. K. Phoon, D. W. Hight and S. Leroueil), pp. 1049-1086. Rotterdam, the Netherlands: Balkema.

Coop, M. R. \& Lee, I. K. (1993). The behaviour of granular soils at elevated stresses. In Predictive soil mechanics (eds G. T. Houlsby, P. Wroth and A. N. Schofield), pp. 186-198. London, UK: Thomas Telford Ltd.

Daouadji, A. \& Hicher, P. Y. (2009). An enhanced constitutive model for crushable granular materials. Int. J. Numer. Analyt. Methods Geomech. 34, No. 6, 555-580.

de Bono, J. P. \& McDowell, G. R. (2014). DEM of triaxial tests on crushable sand. Granular Matter 16, No. 4, 551-562.

Einav, I. (2007). Breakage mechanics - part I: theory. J. Mech. Phys. Solids 55, No. 6, 1274-1297.

Gajo, A. \& Wood, M. (1999). Severn-Trent sand: a kinematic-hardening constitutive model: the $q-p$ formulation. Géotechnique 49, No. 5, 595-614, https://doi.org/10.1680/ geot.1999.49.5.595.

Ghafghazi, M., Shuttle, D. A. \& DeJong, J. T. (2014). Particle breakage and the critical state of sand. Soils Found. 54, No. 3, $451-461$.

Gu, X., Huang, M. \& Qian, J. (2014). DEM investigation on the evolution of microstructure in granular soils under shearing. Granular Matter 16, No. 1, 91-106.

Hanley, K. J., O'Sullivan, C. \& Huang, X. (2015). Particle-scale mechanics of sand crushing in compression and shearing using DEM. Soils Found. 55, No. 5, 1100-1112.

Huang, X., Hanley, K. J., O’Sullivan, C. \& Kwok, C. Y. (2014a). Exploring the influence of interparticle friction on critical state behaviour using DEM. Int. J. Numer. Analyt. Methods Geomech. 38, No. 12, 1276-1297.

Huang, X., Hanley, K. J., O’Sullivan, C. \& Kwok, F. C. Y. (2014b). Effect of sample size on the response of DEM samples with a realistic grading. Particuology 15, 107-115.

Huang, X., O'Sullivan, C., Hanley, K. J. \& Kwok, C. Y. (2014c). Discrete-element method analysis of the state parameter. Géotechnique 64, No. 12, 954-965, https://doi.org/10.1680/ geot.14.P.013.

Huang, X., Hanley, K. J., O’Sullivan, C. \& Kwok, C. Y. (2017). Implementation of rotational resistance models: a critical appraisal. Particuology 34, 14-23.

Indraratna, B., Sun, Q. D. \& Nimbalkar, S. (2015). Observed and predicted behaviour of rail ballast under monotonic loading capturing particle breakage. Can. Geotech. J. 52, No. 1, 73-86.

Itasca (2017). PFC-particle flow code, ver. 5.0. Minneapolis, MN, USA: Itasca Consulting Group.

Jefferies, M. G. (1993). Nor-sand: a simple critical state model for sand. Géotechnique 43, No. 1, 91-103, https://doi.org/10.1680/ geot.1993.43.1.91.

Jefferies, M. \& Been, K. (2015). Soil liquefaction: a critical state approach, 2nd edn. Boca Raton, FL, USA: CRC Press.

Kikumoto, M., Wood, D. M. \& Russell, A. (2010). Particle crushing and deformation behaviour. Soils Found. 50, No. 4, 547-563.

Klotz, E. \& Coop, M. (2002). On the identification of critical state lines for sands. Geotech. Testing J. 25, No. 3, 289-302.

Kuhn, M. R. (2016). The critical state of granular media: convergence, stationarity and disorder. Géotechnique 66 , No. 11, 902-909, https://doi.org/10.1680/jgeot.16.P.008.

Leung, C. F., Lee, F. H. \& Yet, N. S. (1996). The role of particle breakage in pile creep in sand. Can. Geotech. J. 33, No. 6, 888-898.

Li, X. S. \& Wang, Y. (1998). Linear representation of steady-state line for sand. J. Geotech. Geoenviron. Engng 124, No. 12, 1215-1217.

Li, G., Liu, Y. J., Dano, C. \& Hicher, P. Y. (2015). Gradingdependent behavior of granular materials: from discrete to continuous modeling. J. Engng Mech. 141, No. 6, 4014172.

Liu, H. \& Zou, D. (2013). Associated generalized plasticity framework for modeling gravelly soils considering particle breakage. J. Engng Mech. 139, No. 5, 606-615.

Lo, K. Y. \& Roy, M. (1973). Response of particulate materials at high pressures. Soils Found. 13, No. 1, 61-76.
Luong, M. P. \& Touati, A. (1983). Sols grenus sous fortes contraintes. Revue Française de Géotechnique 24, 51-63.

Manzari, M. T. \& Dafalias, Y. F. (1997). A critical state two-surface plasticity model for sands. Géotechnique 47, No. 2, 255-272, https://doi.org/10.1680/geot.1997.47.2.255.

McDowell, G. R. (2002). On the yielding and plastic compression of sand. Soils Found. 42, No. 1, 139-145.

McDowell, G. R. \& De Bono, J. P. (2013). On the micro mechanics of one-dimensional normal compression. Géotechnique 63, No. 11, 895-908, https://doi.org/10.1680/geot.12.P.041.

Muir Wood, D. (2007). The magic of sands - the 20th Bjerrum Lecture presented in Oslo, 25 November 2005. Can. Geotech. J. 44, No. 11, 1329-1350.

Muir Wood, D. \& Maeda, K. (2008). Changing grading of soil: effect on critical states. Acta Geotechnica 3, 3-14.

Nakata, Y., Hyodo, M., Hyde, A. F., Kato, Y. \& Murata, H. (2001). Microscopic particle crushing of sand subjected to high pressure one-dimensional compression. Soils Found. 41, No. 1, 69-82.

Nguyen, H. B. K., Rahman, M. M. \& Fourie, A. B. (2017). Undrained behaviour of granular material and the role of fabric in isotropic and $K$ o consolidations: DEM approach. Géotechnique 67, No. 2, 153-167, https://doi.org/10.1680/ jgeot.15.P.234.

O'Sullivan, C. (2011). Particulate discrete element modelling. London, UK: Taylor \& Francis.

Pender, M. J., Wesley, L. D., Larkin, T. J. \& Satyawan, P. (2006). Geotechnical properties of a pumice sand. Soils Found. 46, No. 1, 69-81.

Roscoe, K. H., Schofield, A. N. \& Wroth, C. P. (1958). On the yielding of soils. Géotechnique 8, No. 1, 22-53, https://doi.org/ 10.1680/geot.1958.8.1.22.

Russell, A. R. \& Khalili, N. (2004). A bounding surface plasticity model for sands exhibiting particle crushing. Can. Geotech. J. 41, No. 6, 1179-1192.

Russell, A. R. \& Muir Wood, D. (2009). Point load tests and strength measurements for brittle spheres. Int. J. Rock Mech. Min. Sci. 46, No. 2, 272-280.

Seif El Dine, B., Dupla, J. C., Frank, R., Canou, J. \& Kazan, Y. (2010). Mechanical characterization of matrix coarse-grained soils with a large-sized triaxial device. Can. Geotech. J. 47, No. 4, $425-438$.

Taylor, D. W. (1948). Fundamentals of soil mechanics. New York, NY, USA: John Wiley and Sons, Inc.

Tengattini, A., Das, A. \& Einav, I. (2016). A constitutive modelling framework predicting critical state in sand undergoing crushing and dilation. Géotechnique 66, No. 9, 695-710, https://doi.org/10.1680/jgeot.14.P.164.

Thornton, C. (2000). Numerical simulations of deviatoric shear deformation of granular media. Géotechnique 50, No. 1, 43-53, https://doi.org/10.1680/geot.2000.50.1.43.

Ting, J. M., Corkum, B. T., Kauffman, C. R. \& Greco, C. (1989). Discrete numerical model for soil mechanics. J. Geotech. Engng 115, No. 3, 379-398.

Vaid, Y. P. \& Sasitharan, S. (1992). The strength and dilatancy of sand. Can. Geotech. J. 29, No. 3, 522-526.

Xiao, Y., Liu, H., Ding, X., Chen, Y., Jiang, J. \& Zhang, W. (2016). Influence of particle breakage on critical state line of rockfill material. Int. J. Geomech. 16, No. 1, 4015031.

Yamamuro, J. A. \& Lade, P. V. (1996). Drained sand behavior in axisymmetric tests at high pressures. J. Geotech. Engng 122, No. 2, 109-119.

Yan, W. M. \& Dong, J. (2011). Effect of particle grading on the response of an idealized granular assemblage. Int. J. Geomech. 11, No. 4, 276-285.

Yang, Z. X., Jardine, R. J., Zhu, B. T., Foray, P. \& Tshua, H. C. (2010). Sand grain crushing and interface shearing during displacement pile installation in sand. Géotechnique 60, No. 6, 469-482, https://doi.org/10.1680/geot.2010.60.6.469.

Yu, H. S. (1998). CASM: a unified state parameter model for clay and sand. Int. J. Numer. Analyt. Methods Geomech. 22, No. 8, $621-653$. 